U.S. Department of Energy Vehicle Technologies, EE-2G

1000 Independence Avenue, S.W.

Washington, D.C. 20585-0121

FY 2009

\title{
Direct-Cooled Power Electronics Substrate
}

Prepared by:

Oak Ridge National Laboratory

Mitch Olszewski, Program Manager

\section{Submitted to:}

Energy Efficiency and Renewable Energy

Vehicle Technologies Program

Susan A. Rogers, Technology Development Manager

December 2008 


\title{
Energy and Transportation Science Division
}

\section{Direct-Cooled Power Electronics Substrate}

ORNL Team Members:

\author{
Randy Wiles \\ Curt Ayers \\ Andrew Wereszczak \\ Kirk Lowe \\ University of Tennessee-Knoxville
}

Publication Date: December 2008

Prepared by the OAK RIDGE NATIONAL LABORATORY

Oak Ridge, Tennessee 37831 managed by UT-BATTELLE, LLC for the 


\title{
DOCUMENT AVAILABILITY
}

Reports produced after January 1, 1996, are generally available free via the U.S. Department of Energy (DOE) Information Bridge:

Web site: http://www.osti.gov/bridge

Reports produced before January 1, 1996, may be purchased by members of the public from the following source:

\author{
National Technical Information Service \\ 5285 Port Royal Road \\ Springfield, VA 22161 \\ Telephone: 703-605-6000 (1-800-553-6847) \\ TDD: $703-487-4639$ \\ Fax: 703-605-6900 \\ E-mail: info@ntis.fedworld.gov \\ Web site: http://www.ntis.gov/support/ordernowabout.htm
}

Reports are available to DOE employees, DOE contractors, Energy Technology Data Exchange (ETDE) representatives, and International Nuclear Information System (INIS) representatives from the following source:

Office of Scientific and Technical Information

P.O. Box 62

Oak Ridge, TN 37831

Telephone: 865-576-8401

Fax: 865-576-5728

E-mail: reports@osti.gov

Web site: http://www.osti.gov/contact.html

This report was prepared as an account of work sponsored by an agency of the United States Government. Neither the United States government nor any agency thereof, nor any of their employees, makes any warranty, express or implied, or assumes any legal liability or responsibility for the accuracy, completeness, or usefulness of any information, apparatus, product, or process disclosed, or represents that its use would not infringe privately owned rights. Reference herein to any specific commercial product, process, or service by trade name, trademark, manufacturer, or otherwise, does not necessarily constitute or imply its endorsement, recommendation, or favoring by the United States Government or any agency thereof. The views and opinions of authors expressed herein do not necessarily state or reflect those of the United States Government or any agency thereof. 


\section{CONTENTS}

Page

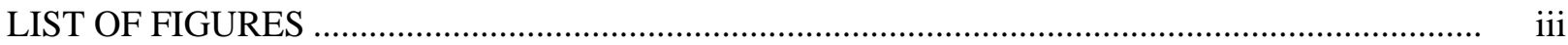

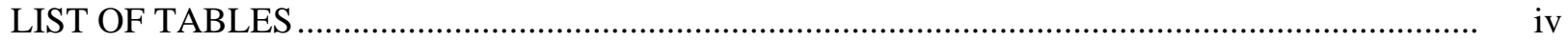

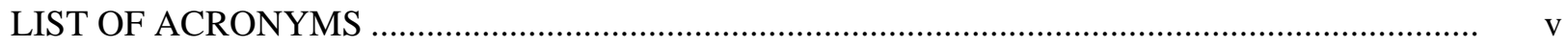

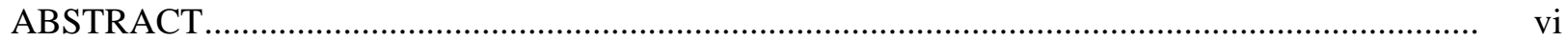

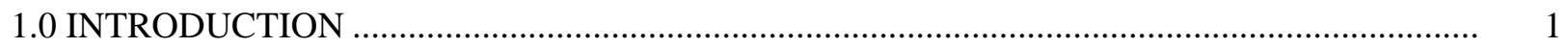

2.0 CANDIDATE PROCESSING METHODS AND MATERIALS FOR

A DIRECT-COOLED POWER ELECTRONICS SUBSTRATE …........................................ 2

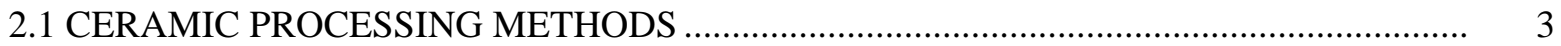

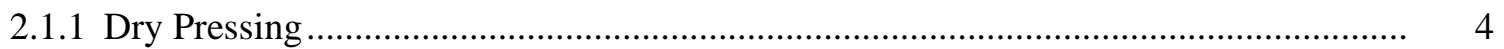

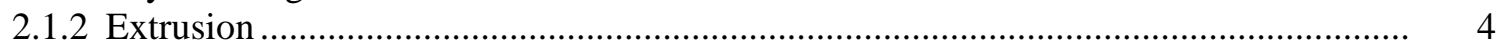

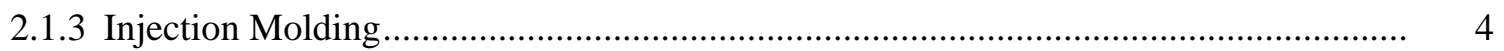

2.1.4 Ceramatec Process .......................................................................................................... 5

3.0 DETERMINE THE OPTIMUM CERAMIC MATERIAL FOR MAXIMUM HEAT

4.0 DESIGN SELECTION

4.1 SELECT CHIP SETS THAT WILL MEET THE INVERTER POWER REQUIREMENT .. 10

4.2 ESTABLISH DESIGN PARAMETERS FOR FEA ON 3-DIMENSIONAL MODELS FOR HEAT TRANSFER OPTIMIZATION

4.2.1 Determine Appropriate Thermal Load for 3-D Models .............................................. 10

4.2.2 Justification of Number of Chips to Use for Specific Designs ....................................... 11

4.2.3 Method of Determining a Successful Chip Layout...................................................... 12

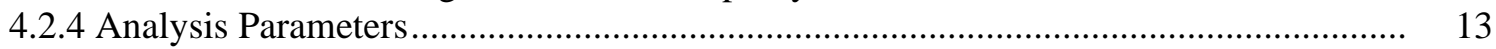

5.0 THERMAL FEA ANALYSIS RESULTS OF 3-D DESIGNS

5.1 THERMAL PERFORMANCE OF DESIGN 1 WITH OPEN FLOW THROUGH 24 FLOW CHANNELS, 1.27 MM DIAMETER ................................................................ 14

5.2 THERMAL PERFORMANCE OF DESIGN 2 WITH FLOW THROUGH FOUR HOLES FILLED WITH A POROUS METALLIC FOAM INSERT, 5.4 MM DIAMETER. 15

5.3 THERMAL PERFORMANCE OF DESIGN 3 WITH FLOW THROUGH ONE FLOW CHANNEL FILLED WITH A POROUS METALLIC FOAM INSERT, 9 MM DIAMETER

5.4 THERMAL PERFORMANCE OF DESIGN 4 WITH FLOW THROUGH A ANNULAR FLOW CHANNEL FILLED WITH A POROUS METALLIC FOAM INSERT

5.5 THERMAL PERFORMANCE OF DESIGN 5 WITH FLOW THROUGH FOUR HOLES FILLED WITH A POROUS METALLIC FOAM INSERT, 9.8 MM DIAMETER .............. 25

6.0 DESIGN CONCLUSION

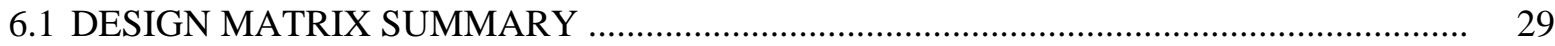

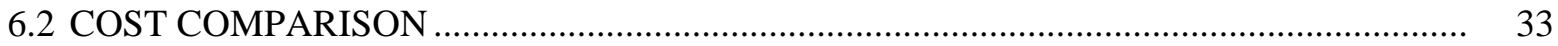

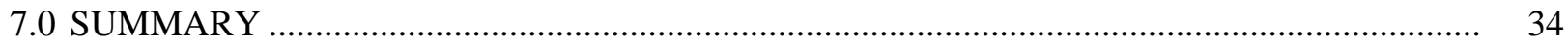

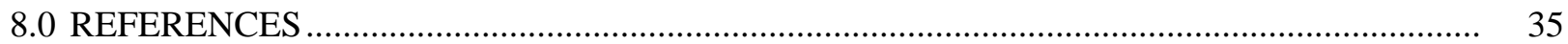

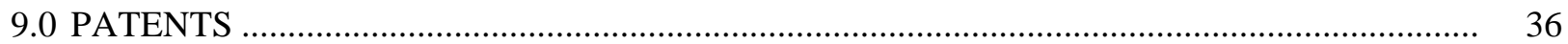

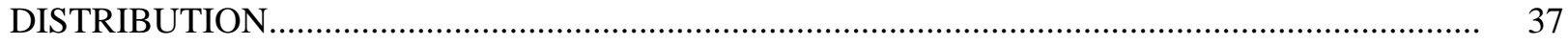




\section{LIST OF FIGURES}

Figure

Page

1 Conceptual rendering of a direct-cooled power electronic substrate

2

2 Conceptual rendering of the hexagonally shaped substrate and photograph of a machines prototype.

Examples of ceramic injection molded parts and the fine features that can be achieved

Examples

WEG impingement on AlN surface shows evidence of chemical reaction

Electrical resistivity domains.....

Electrical resistivity of candidate ceramic materials at $25^{\circ} \mathrm{C}$

Electrical resistivity of candidate ceramic materials at $200^{\circ} \mathrm{C}$

Electrical resistivity of candidate ceramic materials at $325^{\circ} \mathrm{C}$

Waste heat produced by Semikron inverter for different output powers .............................. 11

Possible diode placements on hexagonal substrate.

Sketch of flow channel geometry relative to hexagon subsection with symmetric

geometry noted

Temperature distributions for Design 1 with a load of 55 W ..

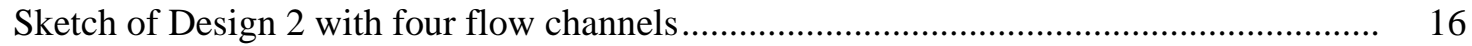

Temperature distributions in Design 2 with cop

Sketch of Design 3 with one flow channel

Temperature distributions in Design 3 with copper foam insert..

18 Sketch of annular geometry ....

19 Maximum interface and fluid temperature for annular flow channel geometry with aluminum foam, $\mathrm{D}=3.4 \mathrm{~mm}$ and $\mathrm{A}=5 \mathrm{~mm}$

Temperature distribution in Design 4, $24 \mathrm{~mm}$ face width alumina ceramic with

annular flow channel geometry

One-twelfth thermo-mechanical FEA model of Design 4, $24 \mathrm{~mm}$ face width alumina ceramic with annular flow channel geometry.....

Material properties used in the thermo-mechanical FEA model ......

First-principles stresses in the $\mathrm{Al}_{2} \mathrm{O}_{3}$ ceramic substrate (Design 4).................................. 24

作 channels with each channel offset $2 \mathrm{~mm}$ from chip center........................................... 27 


\section{LIST OF TABLES}

Table

Page

1 Comparison of candidate ceramic processing methods for a direct-cooled power

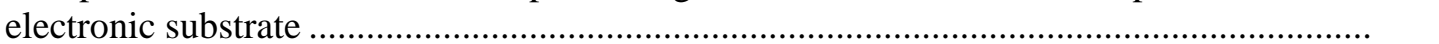

2 Comparison of candidate ceramic materials for a direct-cooled power electronic substrate

Candidate ceramic manufacturers for the direct-cooled power electronic substrate

Boiling points for 50/50 mixture of WEG

9

Material properties used in FEA analysis modeling parameters ..

13

Properties of flow channel with copper foam and aluminum foam insert ........................... 16

Design 1 matrix summary.............................................................................................. 29

Design 2 matrix summary using copper foam................................................................. 30

Design 2 matrix summary using aluminum foam .......................................................... 30

Design 3 matrix summary using copper foam ................................................................ 31

Design 3 matrix summary using aluminum foam............................................................ 31

Design 4 matrix summary using aluminum foam............................................................. 32

Design 5 matrix summary using aluminum foam............................................................. 32

14 Cost summary for ceramic materials considered in the fabrication of a direct-cooled

power electronics substrate 


\section{LIST OF ACRONYMS}

$\begin{array}{ll}{ }^{\circ} \mathrm{C} & \text { degrees Celsius } \\ { }^{\circ} \mathrm{C} / \mathrm{W} & \text { degrees Celsius per Watt } \\ \mu \mathrm{m} & \text { micro-meter } \\ \mathrm{AlN} & \text { aluminum nitride } \\ \mathrm{Al}_{2} \mathrm{O}_{3} & \text { aluminum oxide or alumina } \\ \mathrm{BeO} & \text { beryllium oxide } \\ \mathrm{CARES} & \text { Ceramic Analysis and Reliability Evaluation of Structures } \\ \mathrm{DBC} & \text { direct bonded copper } \\ \mathrm{EG} & \text { ethylene glycol } \\ \mathrm{FEA} & \text { finite element analysis } \\ \mathrm{GPM} & \text { gallons per minute } \\ \mathrm{HEV} & \text { hybrid electric vehicle } \\ \mathrm{ICE} & \text { internal combustion engine } \\ \mathrm{IGBT} & \text { insulated gate bipolar transistor } \\ \mathrm{kg} & \text { kilogram } \\ \mathrm{kg} / \mathrm{m}^{3} & \text { kilogram per cubic meter } \\ \mathrm{kW} & \text { kilowatt } \\ \mathrm{MPa} & \text { mega Pascal } \\ \mathrm{OEMs} & \text { original equipment manufacturers } \\ \mathrm{PHEV} & \text { plug-in hybrid electric vehicles } \\ \mathrm{psig} & \text { pounds per square inch gauge } \\ \mathrm{POS} & \text { probability of survival } \\ \mathrm{Si}{ }_{3} \mathrm{~N}_{4} & \text { silicon nitride } \\ \mathrm{SiC} & \text { silicon carbide } \\ \mathrm{TIM} & \text { thermal interface material } \\ \mathrm{W} & \text { Watt } \\ \mathrm{W} / \mathrm{mK} & \text { Watts per meter Kelvin } \\ \mathrm{WEG} & \text { water-ethylene glycol }\end{array}$




\begin{abstract}
The goal of the Direct-Cooled Power Electronics Substrate project is to reduce the size and weight of the heat sink for power electronics used in hybrid electric vehicles (HEVs) and plug-in hybrid electric vehicles (PHEVs). The concept proposed in this project was to develop an innovative power electronics mounting structure, model it, and perform both thermal and mechanical finite-element analysis (FEA). This concept involved integrating cooling channels within the direct-bonded copper (DBC) substrate and strategically locating these channels underneath the power electronic devices. This arrangement would then be directly cooled by water-ethylene glycol (WEG), essentially eliminating the conventional heat sink and associated heat flow path.

The concept was evaluated to determine its manufacturability, its compatibility with WEG, and the potential to reduce size and weight while directly cooling the DBC and associated electronics with a coolant temperature of $105^{\circ} \mathrm{C}$. This concept does not provide direct cooling to the electronics, only direct cooling inside the DBC substrate itself. These designs will take into account issues such as containment of the fluid (separation from the electronics) and synergy with the whole power inverter design architecture.

In FY 2008, mechanical modeling of substrate and inverter core designs as well as thermal and mechanical stress FEA modeling of the substrate designs was performed, along with research into manufacturing capabilities and methods that will support the substrate designs. In FY 2009, a preferred design(s) will be fabricated and laboratory validation testing will be completed. In FY 2010, based on the previous years laboratory testing, the mechanical design will be modified and the next generation will be built and tested in an operating inverter prototype.
\end{abstract}




\subsection{INTRODUCTION}

As consumer interest grows in hybrid electric vehicles (HEVs) and plug-in hybrid electric vehicles (PHEVs), original equipment manufacturers (OEMs) are challenged to offer these technologies at reduced costs. The automotive manufacturer's goal is to reduce the price of these vehicles relative to the cost of traditional internal combustion engine (ICE) powered vehicles. Thermal management of the power electronic systems that must be implemented into these products constitutes a large cost to both manufacturers and consumers. Currently, HEVs utilize two cooling loops. One cooling loop is for the ICE, which operates at approximately $105^{\circ} \mathrm{C}$, and a second is for the power electronics modules, which operates near $70^{\circ} \mathrm{C}$. One way to significantly reduce the cost to both manufacturers and consumers is to only use a single coolant loop for both the ICE and power electronics using $105^{\circ} \mathrm{C}$ coolant as the primary means of heat dissipation.

Current HEV products containing power modules and state-of-the-art inverters are based on chip and wire assembly and direct-bonded copper (DBC) on flat ceramic substrates. The unidirectional heat flow path for this type of packaging includes the power electronics (silicon die), solder joint, DBC, base plate, thermal paste or grease, and final heat sink. These are traditionally packaged within a housing and then commonly encapsulated with silicone gels for protection. The many layers involved in the typical package contribute to a large overall thermal resistance between the chip junction and the heat sink, but the major thermal conduction limiter is the thermal grease or other thermal interface material (TIM).

The purpose of this research and development project is to design a direct-cooled power electronics substrate that would enable automotive manufacturers to use solely $105^{\circ} \mathrm{C}$ coolant thus eliminating the secondary coolant loop. Thermal performance and mechanical stress finite-element analyses (FEAs) were performed on design concepts to ensure they satisfied the design criteria for material strength and thermal heat dissipation. Surveys were also performed on manufacturer's capabilities and methods supporting the substrate design and fabrication. 


\subsection{CANDIDATE PROCESSING METHODS AND MATERIALS FOR A DIRECT-COOLED POWER ELECTRONICS SUBSTRATE}

A need for sufficient cooling of automotive power electronics using $105^{\circ} \mathrm{C}$ water-ethylene glycol (WEG) is becoming a reality. This creates a small window for successful cooling because the junction temperature of the silicon insulated gate bipolar transistors (IGBTs) and diodes cannot exceed a peak value of $175^{\circ} \mathrm{C}$ or a continuous temperature of $150^{\circ} \mathrm{C}$. Alternative cooling strategies must be considered to enable cooling of the inverter with $105^{\circ} \mathrm{C}$ WEG. One involves positioning the $105^{\circ} \mathrm{C}$ cooling as close to the IGBT and diode as possible through the use of a (electrically insulating) ceramic heat exchanger.

A heat exchanger concept involving the use of a ceramic is the focus of this research effort. An illustration of this concept is shown in Fig. 1, along with a computer rendering of one of the heat exchangers and a machined prototype shown in Fig. 2. Additional concepts involve the use of foam inserted into the coolant channel to act as a thermal conductivity enhancer. Note that the concept shown (in Fig. 1) also uses a metal foam insert in the four flow channels. In any design case, the ceramic in the heat exchanger would serve the same primary role as a ceramic in a conventional DBC, namely an electrical insulator. The substrate would then be metalized with copper to facilitate bonding (e.g., soldering or sintering) to a silicon IGBT and diode.

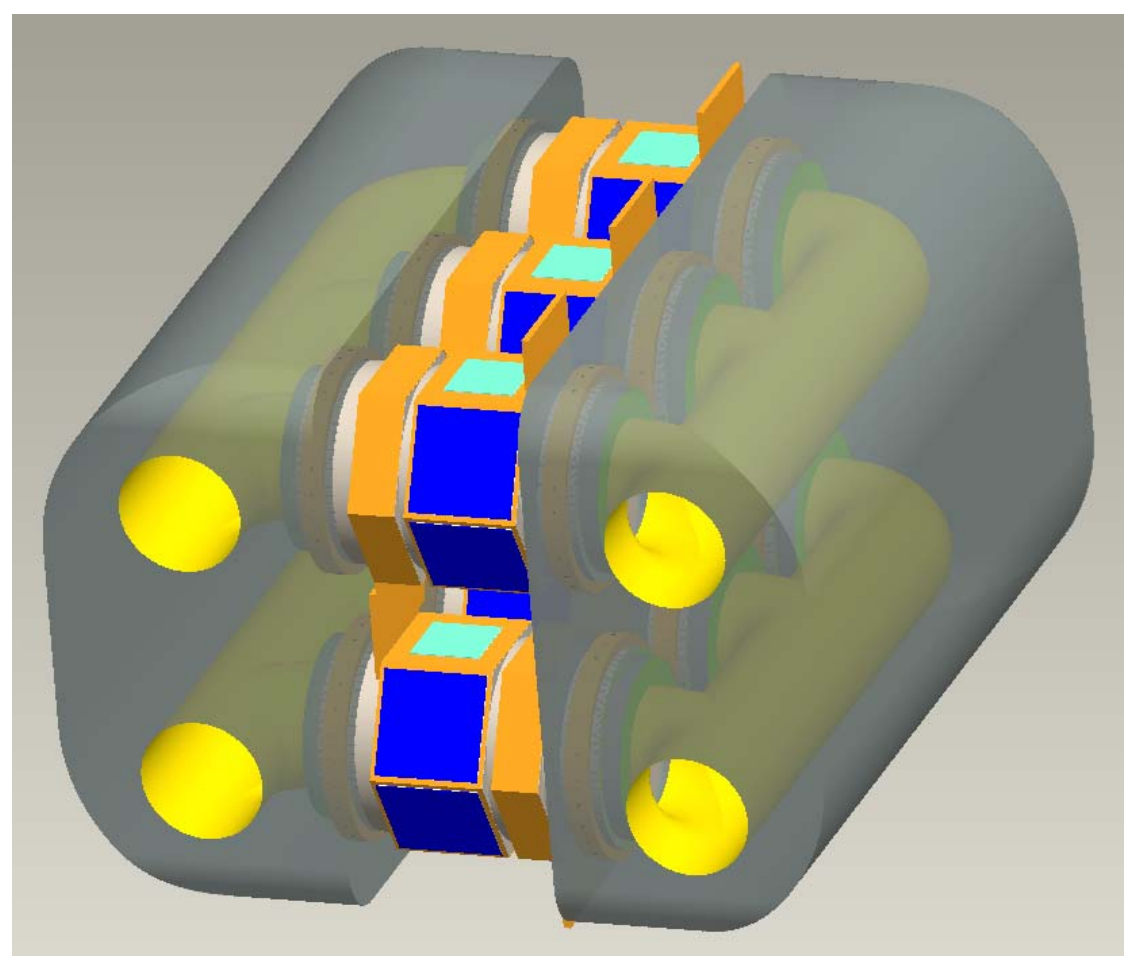

Fig. 1. Conceptual rendering of a direct-cooled power electronic substrate. Six ceramic heat exchangers would provide sustained cooling to 24 IGBTs and 12 diodes. 

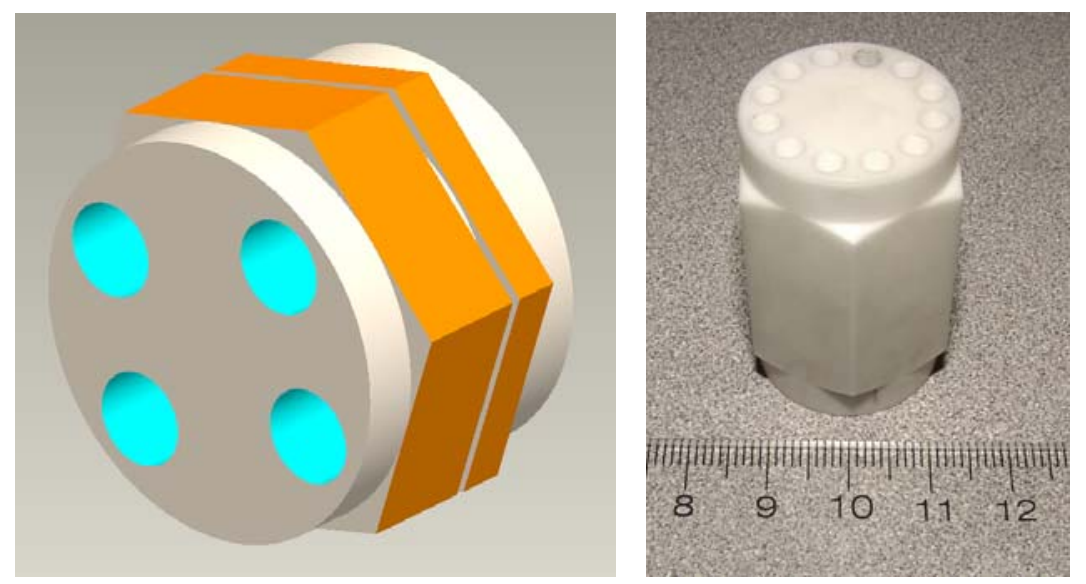

Fig. 2. Conceptual rendering of the hexagonally shaped substrate (left) and photograph of a machined prototype (right).

The following sections describe current state-of-the-art processing methods that satisfy the fabrication requirements as well as candidate ceramic materials.

\subsection{CERAMIC PROCESSING METHODS}

Ceramic processing methods were identified that could be used to produce a direct-cooled DBC. The manufacturing techniques should combine two characteristics: they should be capable of producing smallscale features (e.g., hole diameters of $1 \mathrm{~mm}$ [0.040 in.] or less) in a structure up to $50 \mathrm{~mm}$ in length and be mature processes capable of large-scale manufacturing applicable to the automotive industry. Four identified ceramic processing methods described in the following sections are considered to be "greenstate" fabrication techniques; that is, they are methods that form processed ceramic powder into some desired shape at or near ambient temperature. Their attributes are compared in Table 1.

Table 1. Comparison of candidate ceramic processing methods for a direct-cooled power electronic substrate

\begin{tabular}{|c|c|c|c|c||}
\hline Method & Mature & $\begin{array}{c}\text { Mass } \\
\text { production } \\
\text { capability }\end{array}$ & $\begin{array}{c}\text { Many } \\
\text { companies } \\
\text { use? }\end{array}$ & $\begin{array}{c}\text { Complex } \\
\text { shapes and fine } \\
\text { features? }\end{array}$ \\
\hline Dry pressing & $\mathrm{X}$ & $\mathrm{X}$ & $\mathrm{X}$ & \\
\hline Extrusion & $\mathrm{X}$ & $\mathrm{X}$ & $\mathrm{X}$ & $\mathrm{X}$ \\
\hline $\begin{array}{c}\text { Injection molding } \\
\text { "Ceramatec process" tape } \\
\text { casting + laser machining }+ \\
\text { lamination }\end{array}$ & $\mathrm{X}$ & $\mathrm{X}$ & & $\mathrm{X}$ \\
\hline
\end{tabular}


The "green-processed" component is ultimately sintered (i.e., a solid-state densification process) to final density at elevated temperatures. For ceramics under consideration for this heat exchanger application, sintering temperatures of $1300^{\circ} \mathrm{C}\left(2300^{\circ} \mathrm{F}\right)$ or higher probably would be required. The sintering stage and method are largely independent of the green-state processing method, so their details are not discussed here.

\subsubsection{Dry Pressing}

Dry pressing is one of the most traditional ceramic processing methods. Its advantages are that most ceramic manufacturers are adept at it, it is a mature technology, it is relatively inexpensive, and it is amenable for mass production. Ceramic powder is blended with organics; a die is filled with the powder blend and then uniaxially pressed. Dry pressing by itself could not produce the shape shown in Fig. 2, so manufacturers would perform green-state machining of the dry pressed billet to promote that hexagonal shape and to incorporate the flow channels. Green-state machining is attractive because conventional grinding and machining tools can be used whereas (expensive) diamond tooling is required for machining after a ceramic has been sintered. The sintering process reduces the size of the green-state shape, but manufacturers can accurately take that into account because they are aware of how much reduction occurs for a given ceramic material. The disadvantage of this method is that the architecture may be limited by what can be accomplished during green-state machining; for example, very small thru-hole diameters (e.g., $1 \mathrm{~mm}[0.040 \mathrm{in}$.$] ) may be difficult to produce in the ceramic's green-state and maintain through the$ sintering process.

\subsubsection{Extrusion}

Extrusion is another traditional ceramic processing method. Like dry pressing, its advantages are that many ceramic manufacturers are experienced with it, it is a mature technology, it is relatively inexpensive, and it is amenable for mass production. Ceramic powder is blended with organics to make a plastic body that is then pressurized and forced to pass through a die of the desired cross-section. Like dry pressing, extrusion by itself would not be able to produce the shape shown in Fig. 2; green-state machining would be needed, so fine-scale-features of the final architecture could be limited.

\subsubsection{Injection Molding}

Injection molding can achieve high precision ceramic parts (e.g., $\pm 25 \mu \mathrm{m}= \pm 0.001$ in.) having small or large size, high production volumes (tens of thousands to millions), an almost infinite variety of designs, low labor requirements, and low costs. Another advantage to injection molding is that machining costs can often be eliminated (certainly minimized) once dies and tooling have been optimized. It does not have the limitations inherent to green-state machining of dry-pressed or extruded billets; internal features are not limited by symmetry and can be very complex if desired. For example, a helical pattern can be incorporated in a channel to better promote turbulent flow of a WEG. Examples of the fine architectures achievable with ceramic injection molding are shown in Fig. 3. 

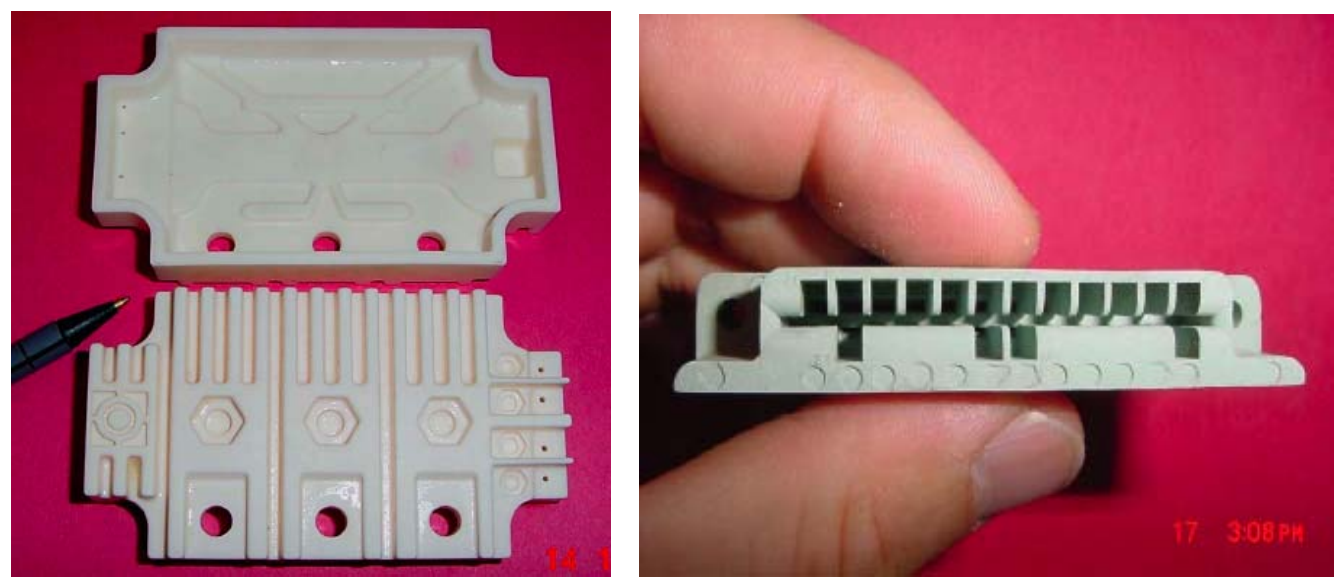

Fig. 3. Examples of ceramic injection molded parts and the fine features that can be achieved. Aluminum oxide IGBT cover (left) and silicon carbide (SiC) electronic part (right). [Images provided by Springboard Ceramic Injection Molding, Pittsfield, MA].

\subsubsection{Ceramatec Process}

The Ceramatec process combines tape casting, laser machining of the green tapes, and lamination to produce ceramic components with complex internal channels. Fine tolerances can be achieved, and the process is mature and under consideration for a wide range of ion transport membrane technologies. Large dimensions are achievable in two of the three dimensions. The mass production capabilities of this process are not as good as for dry pressing, extrusion, or injection molding (Fig. 4).
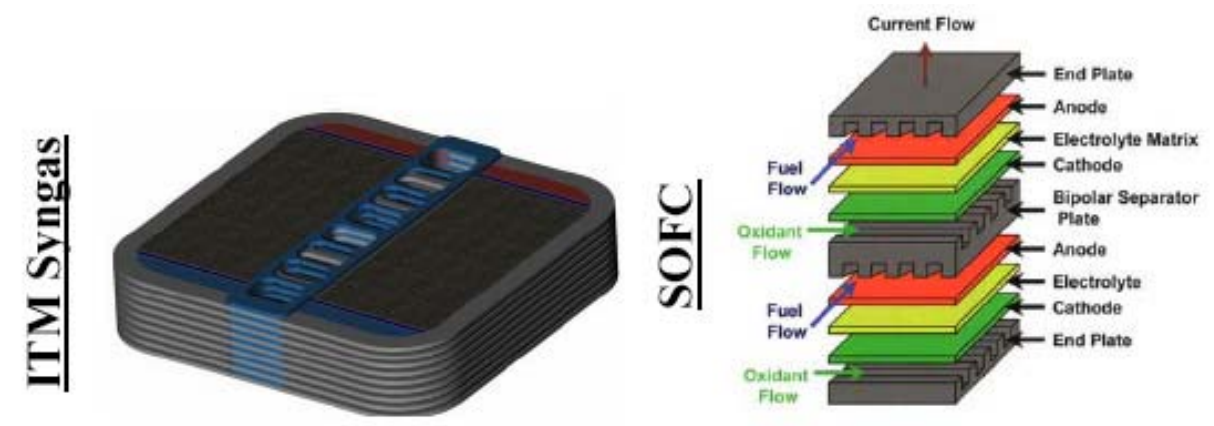

Fig. 4. Examples of fine-scale ceramic architectures fabricated by the Ceramatec process. Laminated ion transport membrane (left) and laminated ceramic solid oxide fuel cell structure (right). [Images provided by M. Ferber, Ceramatec, Salt Lake City, UT]. 


\subsection{DETERMINE THE OPTIMUM CERAMIC MATERIAL FOR MAXIMUM HEAT TRANSFER}

Ceramic materials were sought that combined: electrical insulation $\left(>10^{9} \mathrm{ohm} \bullet \mathrm{cm}\right)$, the potential to be chemically compatible with WEG, good thermal conductivity (>50 W/mK), modest tensile strength (> $200 \mathrm{MPa}$ ), and minimum cost and that could be processed by any of the four methods described earlier. A summary of several candidate ceramics is shown in Table 2.

Table 2. Comparison of candidate ceramic materials for a direct-cooled power electronic substrate

\begin{tabular}{||c|c|c|c|c|}
\hline Candidate ceramic & $\begin{array}{c}\text { Electrical } \\
\text { insulation }\end{array}$ & $\begin{array}{c}\text { Thermal } \\
\text { conductivity }\end{array}$ & Cost & $\begin{array}{c}\text { Chemical } \\
\text { Compatibility with } \\
\text { WEG }\end{array}$ \\
\hline Aluminum oxide or alumina $\left(\mathrm{Al}_{2} \mathrm{O}_{3}\right)$ & Excellent & Fair & Low & $\begin{array}{c}\text { Unknown but } \\
\text { probably good }\end{array}$ \\
\hline Aluminum nitride $(\mathrm{AlN})$ & Excellent & Excellent & High & Unknown \\
\hline Silicon Nitride $\left(\mathrm{Si}_{3} \mathrm{~N}_{4}\right)$ & Excellent & Fair to good & High & Unknown \\
\hline High resistivity polycrystalline $\mathrm{SiC}$ & $\begin{array}{c}\text { Potentially } \\
\text { excellent }\end{array}$ & $\begin{array}{c}\text { Good to } \\
\text { excellent }\end{array}$ & $\begin{array}{c}\text { Medium to } \\
\text { high }\end{array}$ & Unknown \\
\hline Beryllium oxide $(\mathrm{BeO})$ & Excellent & Excellent & Medium & Unknown \\
\hline
\end{tabular}

Some of the candidate ceramic materials are documented [1,2] as being unstable in contact with moisture. The thermal cycling of the material may introduce fatigue when it is in contact with WEG, so a series of strength and fatigue tests were begun on $\mathrm{AlN}, \mathrm{Al}_{2} \mathrm{O}_{3}, \mathrm{Si}_{3} \mathrm{~N}_{4}$, and $\mathrm{SiC}$ after they were immersed in and impinged with WEG. Preliminary indications were that none of the materials had a dramatic decrease in strength from contact with WEG; however, scanning electron microscopy of ceramic surfaces subjected to WEG impingement for 590 hours showed that erosion was occurring probably because of a chemical reaction between the AlN and WEG (see Fig. 5). Longer-term studies are continuing. Additionally, electrical resistivity tests were completed on the designated ceramic candidates at 25,200 , and $325^{\circ} \mathrm{C}$. The results of the electrical resistivity tests are shown in Figs. 6-9. 


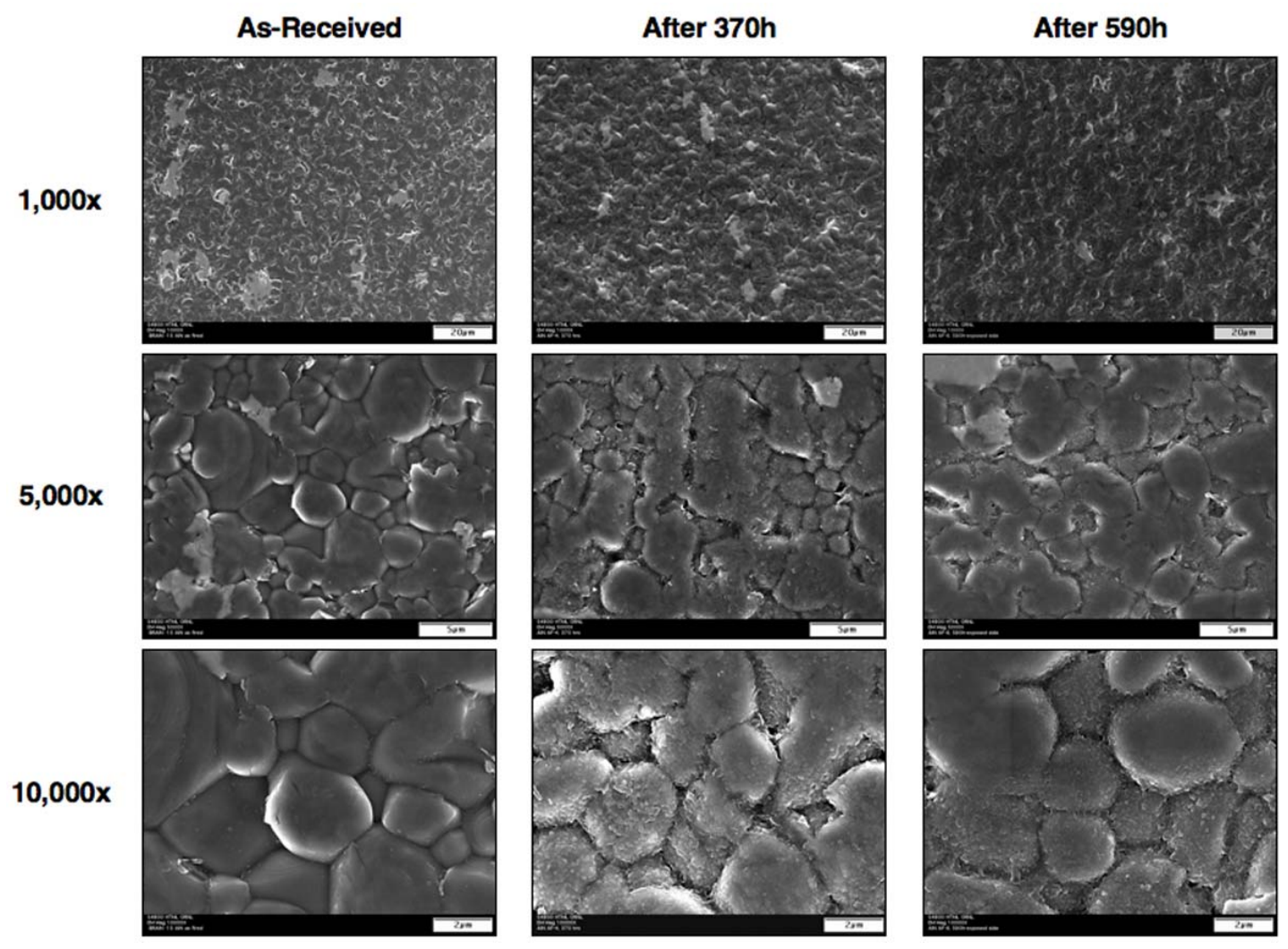

Fig. 5. WEG impingement on AIN surface shows evidence of chemical reaction. Such a reaction can enable erosion.

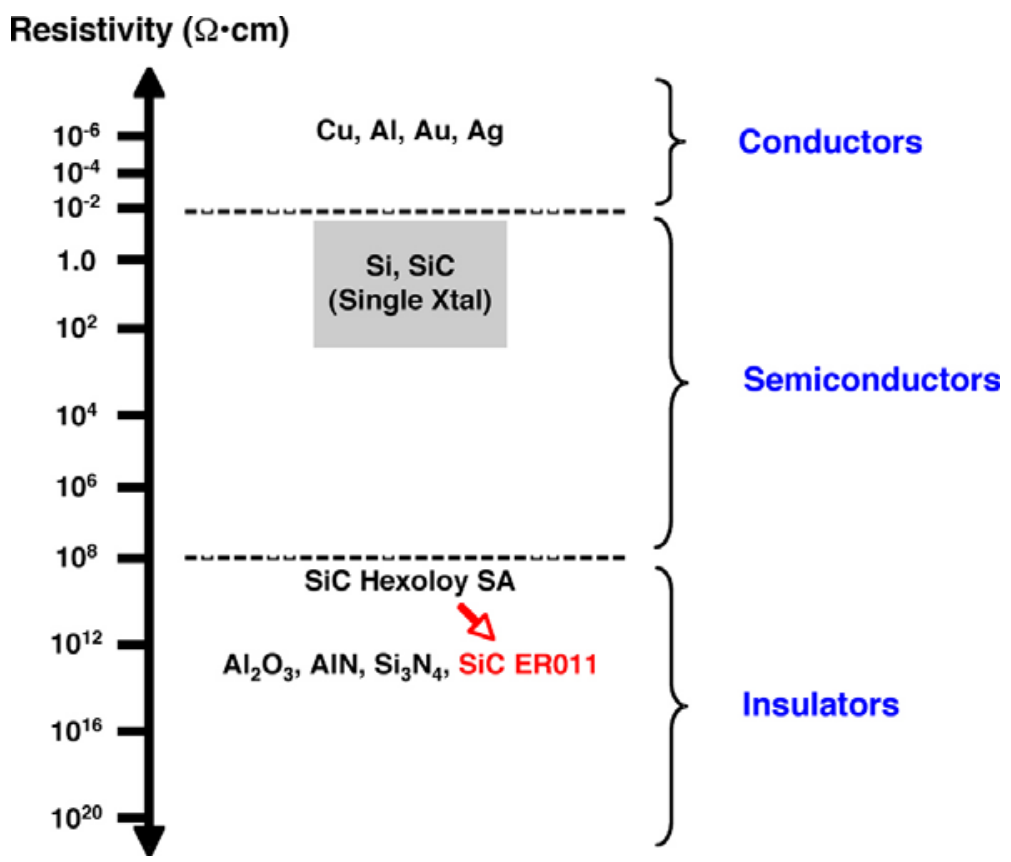

Fig. 6. Electrical resistivity domains. 


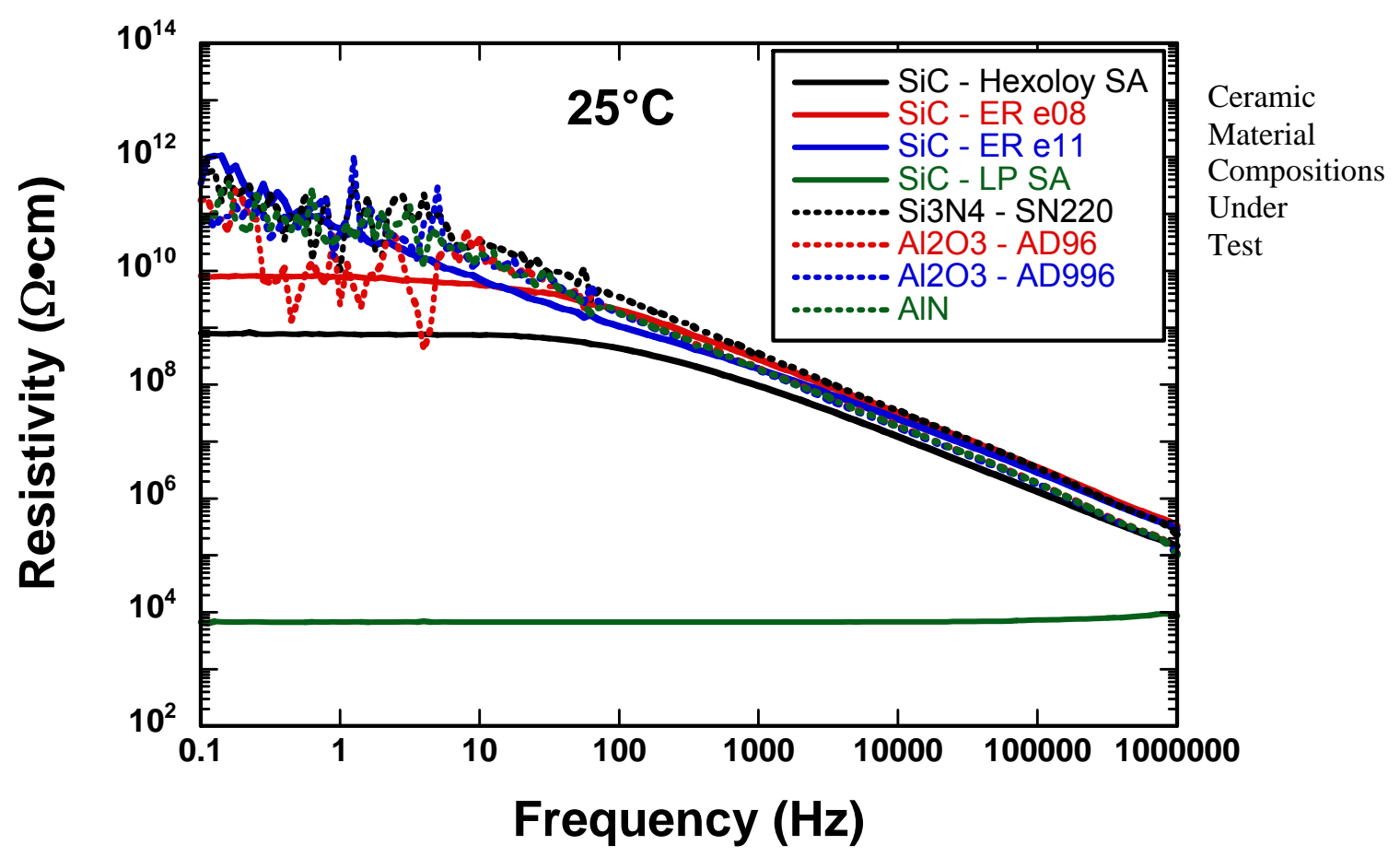

Fig. 7. Electrical resistivity of candidate ceramic materials at $25^{\circ} \mathrm{C}$.

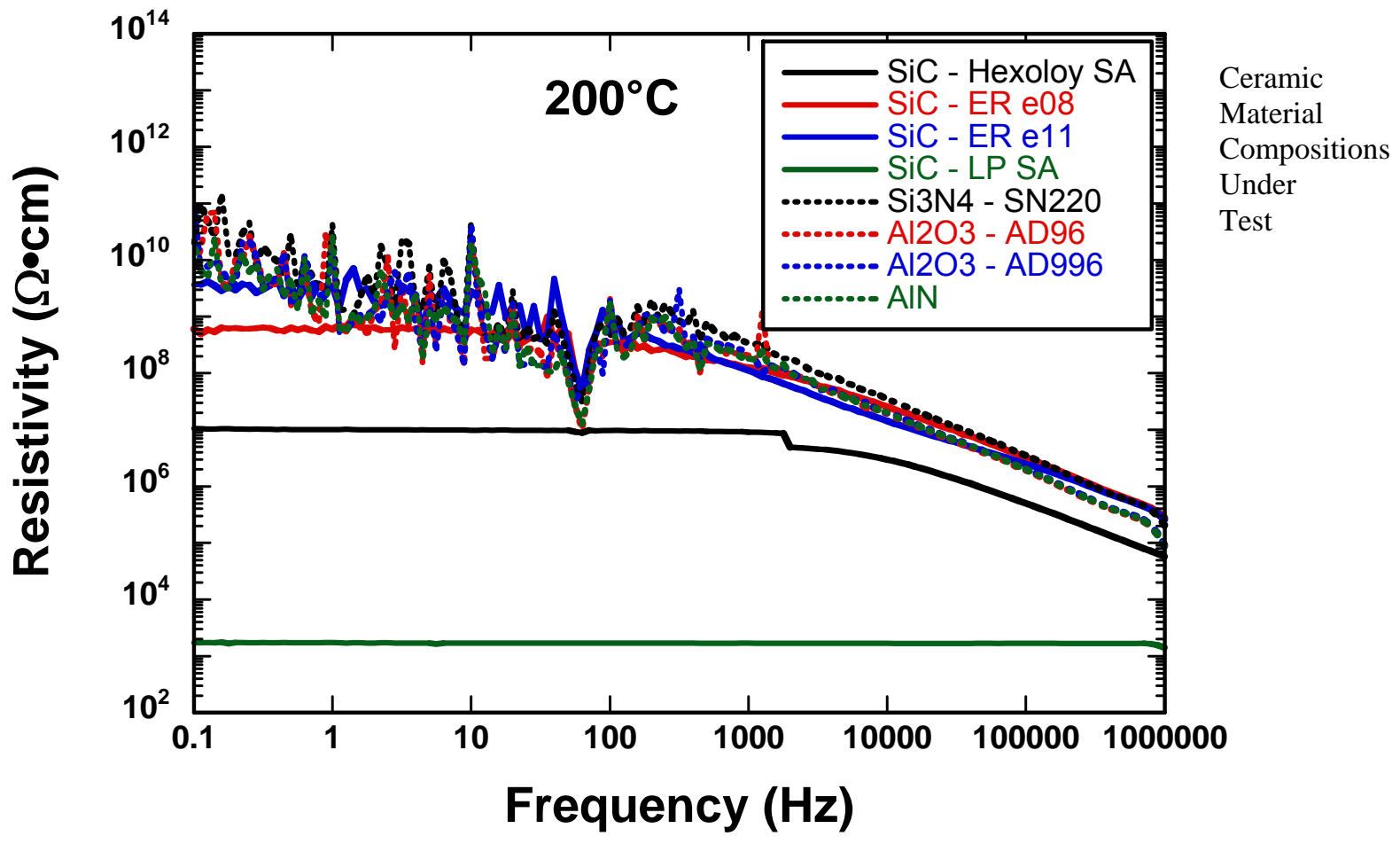

Fig. 8. Electrical resistivity of candidate ceramic materials at $200^{\circ} \mathrm{C}$. 


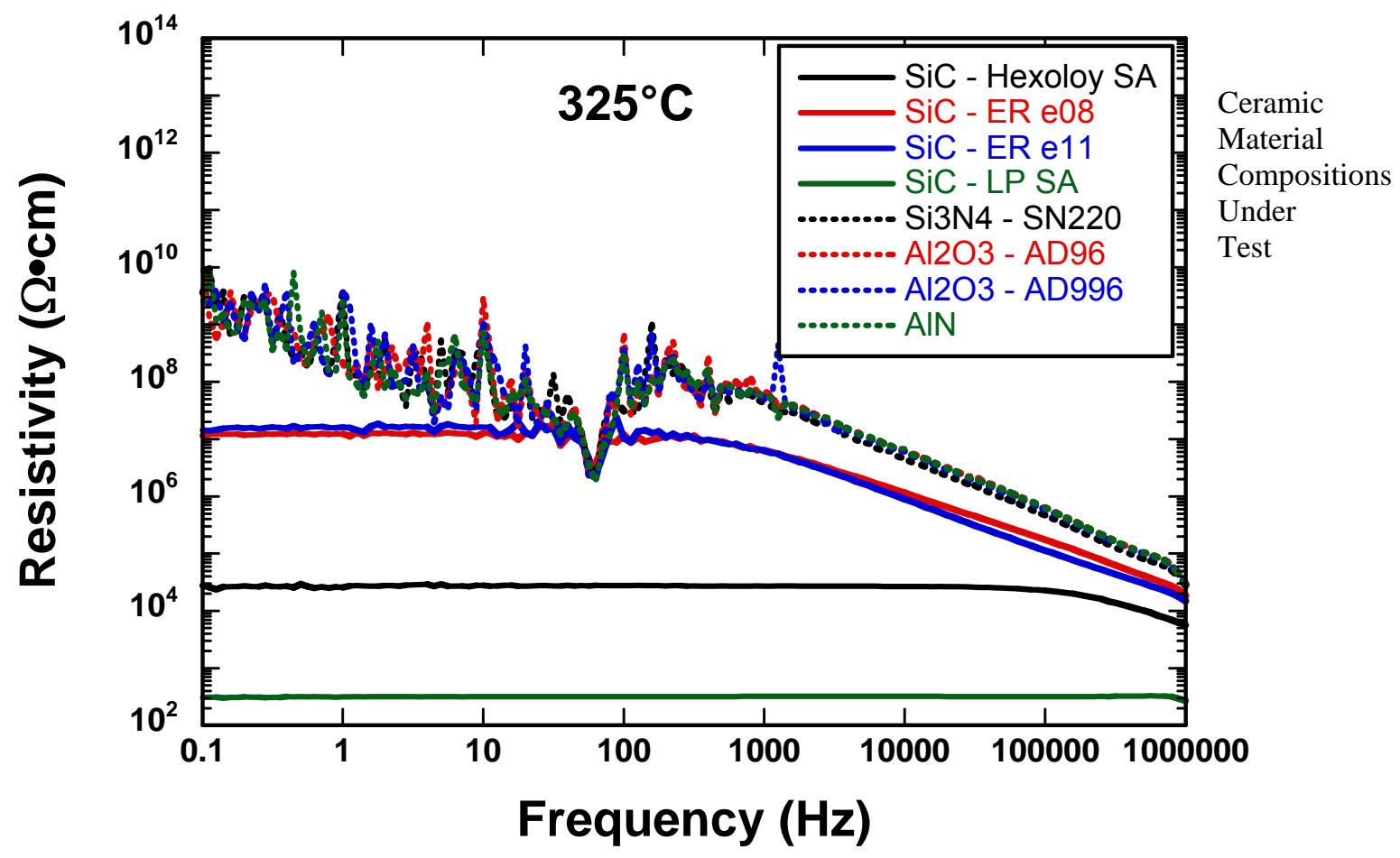

Fig. 9. Electrical resistivity of candidate ceramic materials at $325^{\circ} \mathrm{C}$.

A list of candidate ceramic manufacturers is provided in Table 3. All have large-scale ceramic manufacturing capabilities, presently have sizeable ceramic markets, and could satisfactorily manufacture a heat exchanger like that shown in Fig. 2. All were contacted about the heat exchanger concept, and its manufacturability was discussed.

Table 3. Candidate ceramic manufacturers for the direct-cooled power electronic substrate

\begin{tabular}{||l|l|l|}
\hline \hline Company & Where located? & Ceramics \\
\hline ACR & Tucson, $\mathrm{AZ}$ & $\mathrm{Al}_{2} \mathrm{O}_{3}, \mathrm{AlN}, \mathrm{Si}_{3} \mathrm{~N}_{4}$ \\
\hline Brush Ceramic Products & Tucson, $\mathrm{AZ}$ & $\mathrm{BeO}$ \\
\hline BAE Ceramics (Cercom) & Vista, CA & $\mathrm{Al}_{2} \mathrm{O}_{3}, \mathrm{AlN}, \mathrm{SiC}$ \\
\hline Ceradyne & Costa Mesa, CA & $\mathrm{Al}_{2} \mathrm{O}_{3}, \mathrm{AlN}, \mathrm{Si}_{3} \mathrm{~N}_{4}, \mathrm{SiC}$ \\
\hline Ceramatec & Salt Lake City, UT & $\mathrm{Al}_{2} \mathrm{O}_{3}, \mathrm{AlN}_{\mathrm{Si}_{3} \mathrm{~N}_{4}}$ \\
\hline CoorsTek & Golden, CO & $\mathrm{Al}_{2} \mathrm{O}_{3}$ \\
\hline Kennametal & Latrobe, PA & $\mathrm{Si}_{3} \mathrm{~N}_{4}$ \\
\hline Kyocera & Japan & $\mathrm{Si}_{3} \mathrm{~N}_{4}$ \\
\hline Saint-Gobain & Niagara Falls, $\mathrm{NY}$ & $\mathrm{SiC}$ \\
\hline Springboard CIM & Pittsfield, MA & $\mathrm{Al}_{2} \mathrm{O}_{3}, \mathrm{AlN}, \mathrm{Si}_{3} \mathrm{~N}_{4}, \mathrm{SiC}$ \\
\hline
\end{tabular}




\subsection{DESIGN SELECTION}

\subsection{SELECT CHIP SETS THAT WILL MEET THE INVERTER POWER REQUIREMENT}

A silicon device's primary rating is its current-voltage (I-V) characteristics that dictate how much current the device can conduct at the expense of a forward voltage drop. For IGBTs, these curves depend on the applied gate voltage and junction temperature. For diodes, the characteristic curves are temperature dependent. Likewise the junction temperature of the device is dependent on the packaging and the heat removal rate.

It was determined that a device can conduct rated current up to its maximum rated junction temperature as long as the waste heat being produced is consistently removed. The typical junction-to-case resistance noted in the device literature can involve many internal layers. The thermal efficiency of a multilayered structure is only as good as that of the poorest thermal conductor in that multilayer, and that is usually the TIM. Our liquid-cooled DBC design dramatically reduces the number of thermal resistances including omitting the TIM. Furthermore, using bare chips instead of prepackaged chips allows for more control over the junction temperature.

Typical thermal resistances are $0.3-0.4^{\circ} \mathrm{C} / \mathrm{W}$ when a prepackaged IGBT is used. For a waste heat of approximately $50 \mathrm{~W}$, this would imply a $15-20^{\circ} \mathrm{C}$ rise from case to junction. For our designs, the solder layer and the intrinsic resistance of the silicon are the only contributors to the thermal resistance beyond the bonded copper. For a $100 \mu \mathrm{m}$ thick chip with a cross-sectional area of $121 \mathrm{~mm}^{2}$, the thermal resistance would be $0.0056^{\circ} \mathrm{C} / \mathrm{W}$ corresponding to a $0.3^{\circ} \mathrm{C}$ rise to junction. Lead-tin solder could have a resistance of around $0.02^{\circ} \mathrm{C} / \mathrm{W}$, which would give a $1^{\circ} \mathrm{C}$ rise across the solder joint. The total increase from the interface temperature would be about $1.5^{\circ} \mathrm{C}$ which is an order of magnitude lower than in the prepackaged chip. The lower temperature difference between the junction and interface allows for the maximum amount of current to conduct at much higher "case” temperatures.

IGBTs selected for use in modeling were Infineon Technologies "trench type" IGBTs. This chip has maximum ratings of $600 \mathrm{~V}$ and $200 \mathrm{~A}$. It possesses low $\mathrm{V}_{\mathrm{CE}(\text { sat), }}$ low turn-off losses, short tail current, and positive temperature coefficient and is easily paralleled. Diodes selected for use were Infineon Technologies fast-switching diode chips in EMCON 3-Technology. This chip has maximum ratings of $600 \mathrm{~V}$ and $200 \mathrm{~A}$. It possesses soft, fast switching, a low reverse recovery charge and a small temperature coefficient. Both have temperature operating ranges of $-40^{\circ} \mathrm{C}$ to $175^{\circ} \mathrm{C}$.

\subsection{ESTABLISH DESIGN PARAMETERS FOR FEA ON 3-DIMENSIONAL (3-D) MODELS FOR HEAT TRANSFER OPTIMIZATION}

\subsubsection{Determine Appropriate Thermal Load for 3-D Models}

In previous research and development efforts, two inverter ratings were used in thermal models: $55 \mathrm{~kW}$ peak and $30 \mathrm{~kW}$ continuous. A constant efficiency in the inverter over the entire operational range was also assumed in these previous efforts. Thus the thermal load could be determined for continuous and peak loading. However, these assumptions are not entirely valid. Data from Oak Ridge National Laboratory's (ORNL) Semikron [3] testing shown in Fig. 10 show that waste heat magnitudes can approach maximum values while the output is below the peak power rating. This is due to decreases in efficiencies based on running conditions. 


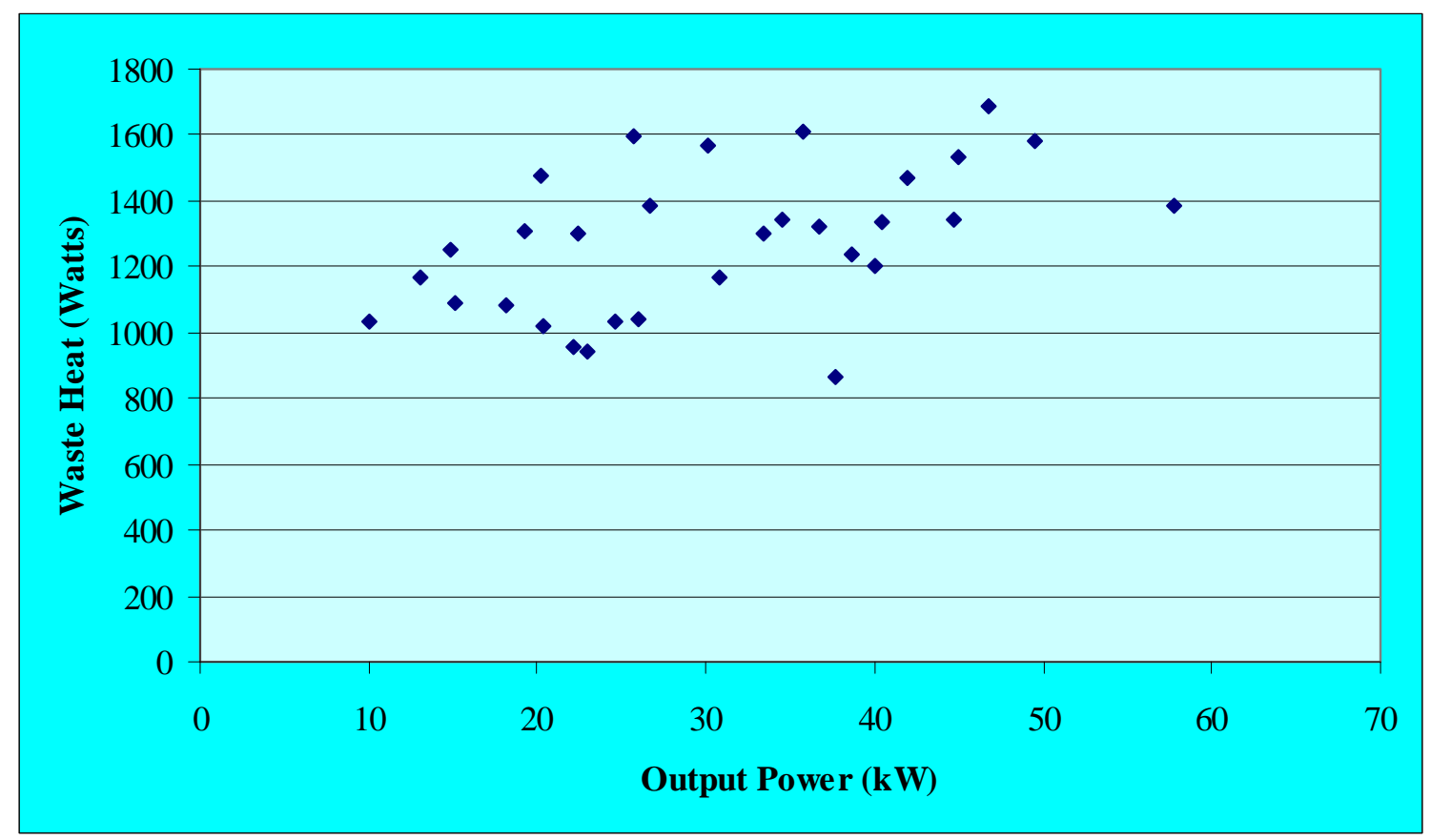

Fig. 10. Waste heat produced by Semikron inverter for different output powers.

An approximate waste heat distribution for this architecture can be found using Semikron testing evaluation results and a maximum waste heat of $1746 \mathrm{~W}$. Assuming that the upper and lower leg of each phase will dissipate equal amounts of energy over an operational period, the heat loss per hexagonal section is $291 \mathrm{~W}$. Each section will have two diodes and three or four IGBTs. It is assumed that the diode losses are about a third of the switch losses. This approximation is based on an application note that Semikron published for an inverter to control electric forklifts [4]. The power range was smaller than for full-size vehicles but the loss ratio should give a good estimate of the loss distribution.

Using this ratio and four IGBTs per section implies that $75 \%$ of the loss will come from the switches and $25 \%$ from the diodes or $54.6 \mathrm{~W}$ per switch and $36.4 \mathrm{~W}$ per diode. If three switches were used, the losses would be $72.75 \mathrm{~W}$ per switch and $36.4 \mathrm{~W}$ per diode. No attempt will be made to justify a continuous operating loss because of the efficiency dependency of the heat losses. Furthermore, using the maximum losses allows the design to be configured for the worst case scenario. The design should then provide more than adequate cooling for transient power fluctuations and continuous load.

\subsubsection{Justification of Number of Chips to Use for Specific Designs}

In this study the heat load for the IGBT was varied to simulate the number of switches used for each half electrical phase. A minimum of three switches is required to achieve the current rating necessary for the inverter. Because the devices are being run at the upper end of their operational range, four switches may be used to spread the losses of the inverter out over a wider area and to add a margin of safety. The computer models will predict the maximum temperatures to determine if the selected chip population is a viable option.

Using the power ratings in the previous discussion, computer models were run using $55 \mathrm{~W}$ and $73 \mathrm{~W}$ per chip for all devices. These heat loads will represent the worst-case scenario for their respective chip population per section. The hexagonal design of the half electrical phase section allows for various placements of the switches and diodes as depicted in Fig. 11. The hexagonal structure was desired 
because it allows for a compact chip layout, provides excellent sealing surfaces, and provides adequate space to incorporate coolant channels. In high-thermal-conductivity materials, the flat of the hexagonal structure was designed to be $12 \mathrm{~mm}$. This provided enough surface area for the switches to be sintered or soldered. When using a lower thermal conductivity material, such as $\mathrm{Al}_{2} \mathrm{O}_{3}$, the flat of the hexagonal structure has to increase. Models showed that it must increase to $24 \mathrm{~mm}$. This was necessary for heat dissipation within the structure. In either case, the length of the entire ceramic structure is $30 \mathrm{~mm}$. This length provides enough surface area for the switches, wire bonds, electrical connections, and sealing surfaces. Substrate sealing issues were another concern. The rounded ends of the hexagonal structure will provide an excellent sealing surface as opposed to the traditional flat plate design currently used. Because of manufacturing restrictions and automotive manufacturer guidelines, typical thin, flat plate DBC substrates are not feasible for this concept of direct cooling. More cross-sectional area had to be created to incorporate flow channels to remove the heat.
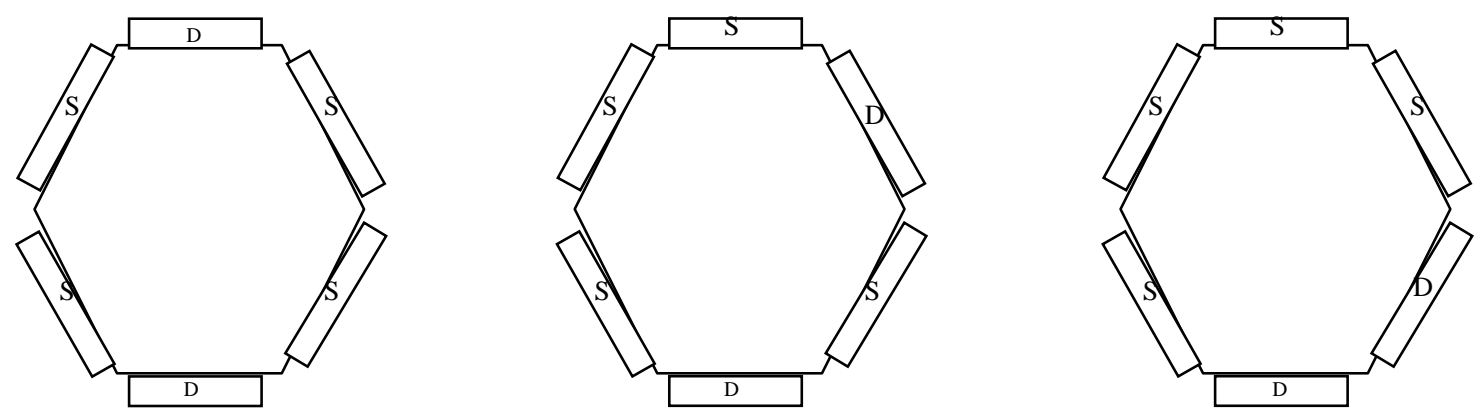

Fig. 11. Possible diode placements on hexagonal substructure.

Various layout options may suggest that full-geometry thermal models are required. However, two switches will always be on adjoining faces. This observation, along with the proximity of the flow channels to the heat source, leads to little variation in maximum temperatures that occur under the IGBTs. The effects of a lower heat loss for one face will result in local cooler regions but should not significantly affect flow channel temperatures under other devices. Furthermore, modeling the temperature distribution for higher losses, where the diodes would be present, adds to the robustness of the design.

\subsubsection{Method of Determining a Successful Chip Layout}

For a design to be considered successful, the thermal models must predict junction temperatures below $175^{\circ} \mathrm{C}$ or even below $150^{\circ} \mathrm{C}$. Also, the coolant temperatures must be maintained below the boiling point of a 50/50 WEG mixture so that OEMs do not have to alter system pressure ratings. Table 4 shows the boiling point for 50/50 mixes of WEG for various system pressures. Typical automotive radiator caps are rated at $12-18$ psig (15-16 is psig more common). Pressure ratings above 18 psig are typically indicative of high-performance parts. The coolant temperature performance criterion used in developing the models was limited to $130^{\circ} \mathrm{C}$, which corresponds to 16 psig. 
Table 4. Boiling point for 50/50 mixtures of WEG

\begin{tabular}{|c|c|}
\hline Coolant pressure & WEG boiling point \\
\hline (psig) & ${ }^{\circ} \mathrm{C}$ \\
\hline 0 & 107.1 \\
\hline 12 & 125.4 \\
\hline 13 & 126.6 \\
\hline 14.7 & 128.6 \\
\hline 16 & 130.0 \\
\hline 20 & 134.1 \\
\hline
\end{tabular}

\subsubsection{Analysis Parameters}

The fluid inlet velocity varied depending on fluid channel size. Initial inlet velocity was consistent with a total inverter flow rate set at 2.5 gallons per minute (GPM). Velocities were then increased for various designs to determine at what flow rate the design met the design intent. This increase in velocity was helpful in determining the preferred designs. Each of the five designs should be able to pass a 1-mm particle through the flow channels; however, filtering of the coolant may be necessary. This will be determined during component testing. Fluid inlet temperature was specified as $105^{\circ} \mathrm{C}$. All other boundaries were modeled as thermally insulated. This assumption allows for a conservative design, and the actual thermal performance should result in lower junction and fluid temperatures because of other minor heat losses. The material properties used in the FEA modeling are listed in Table 5. Thermal conductivity and specific heat are dependent on temperature; however, room-temperature values are shown in Table 5 and were used in the analysis.

Table 5. Material properties used in FEA analysis modeling parameters

\begin{tabular}{|c|c|c|c|c|}
\hline Material & Thermal conductivity & Density & Specific heat & Viscosity \\
\hline & $\mathrm{W} / \mathrm{m}-\mathrm{K}$ & $\mathrm{kg} / \mathrm{m} 3$ & $\mathrm{~J} / \mathrm{kg}-\mathrm{K}$ & $\mathrm{Pa}-\mathrm{s}$ \\
\hline \hline $\mathrm{AlN}$ & 160 & 3260 & 740 & $\mathrm{n} / \mathrm{a}$ \\
\hline $\mathrm{Al}_{2} \mathrm{O}_{3}$ & 25 & 3700 & 800 & $\mathrm{n} / \mathrm{a}$ \\
\hline $\mathrm{BeO}$ & 146 & 2850 & 1046 & $\mathrm{n} / \mathrm{a}$ \\
\hline $\mathrm{Si}_{3} \mathrm{~N}_{4}$ & 40 & 3200 & 700 & $\mathrm{n} / \mathrm{a}$ \\
\hline $\mathrm{SiC}$ sintered polycrystalline & 130 & 3100 & 720 & $\mathrm{n} / \mathrm{a}$ \\
\hline 50/50 EG water & 0.4 & 1006 & 3750 & 0.0006 \\
\hline
\end{tabular}




\subsection{THERMAL FEA ANALYSIS RESULTS OF 3-D DESIGNS}

\subsection{THERMAL PERFORMANCE OF DESIGN 1 WITH OPEN FLOW THROUGH 24 FLOW CHANNELS, 1.27 MM DIAMETER}

In Design 1 shown in Fig. 12, 24 flow channels are placed through the ceramic subsection. They are equally spaced on a bolt circle that maintains a minimum distance of $1.27 \mathrm{~mm}$ [0.050 in.] between surfaces. The minimum distance is maintained to provide structural integrity and is based on ceramic manufacturing limitations. The inlet velocity of the fluid was $0.85 \mathrm{~m} / \mathrm{s}$ which translated to a total inverter flow rate of $2.50 \mathrm{GPM}$. The inlet temperature of the fluid was specified as $105^{\circ} \mathrm{C}$. The darkened triangle represents a thermally symmetric unit cell that was modeled for simplicity.

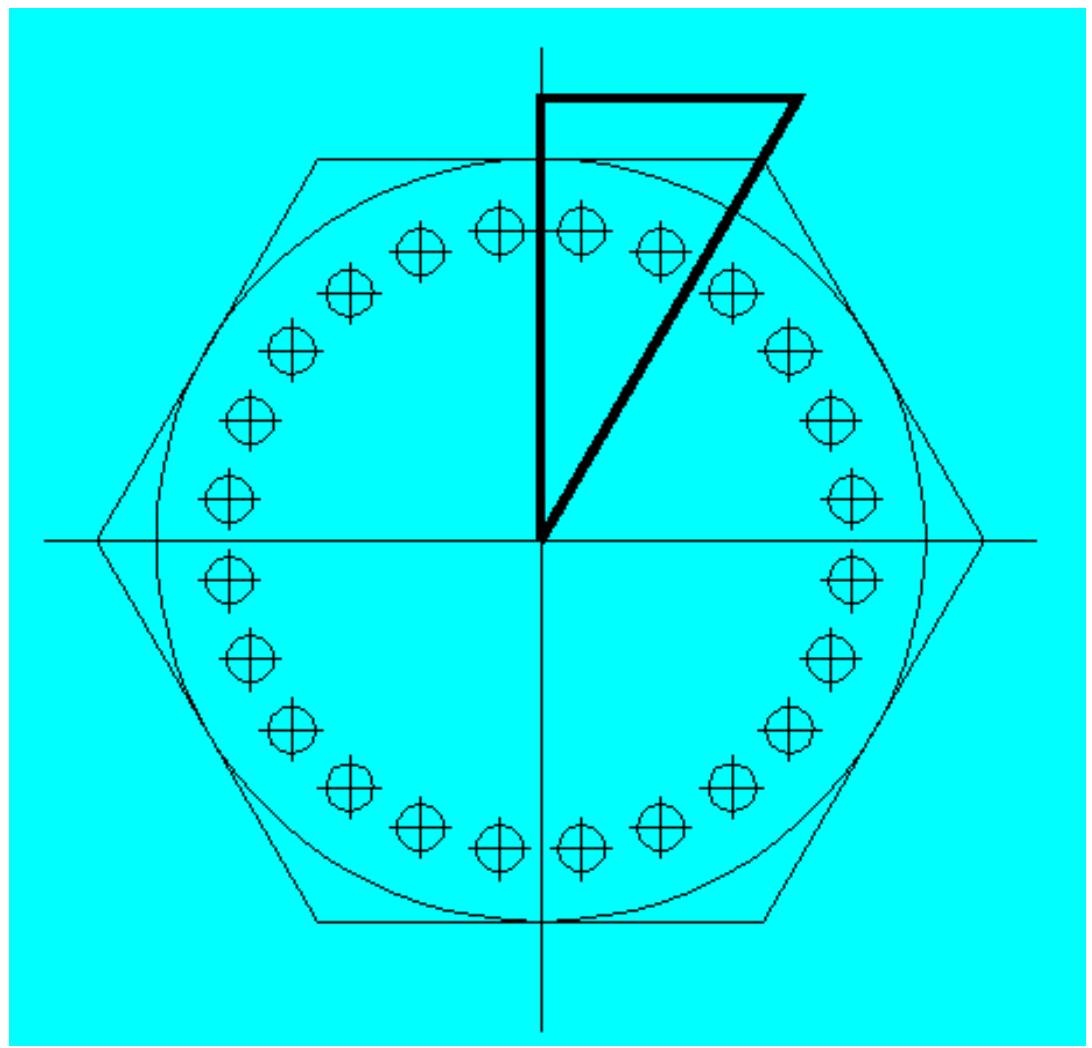

Fig. 12. Sketch of flow channel geometry relative to hexagon subsection with symmetric geometry noted.

In Fig. 13, the open-flow configuration represents the coolest temperature distribution for a load of $55 \mathrm{~W}$ per chip. The maximum projected junction temperature is $141.7^{\circ} \mathrm{C}$, and the maximum fluid temperature is $136.5^{\circ} \mathrm{C}$. The junction temperature represented in the graphical representation is representative of AlN. When $\mathrm{Al}_{2} \mathrm{O}_{3}$ is used, the projected junction temperature is $182.9^{\circ} \mathrm{C}$ and the maximum fluid temperature is $163.0^{\circ} \mathrm{C}$. With $\mathrm{SiC}$, the projected junction temperature is $144.7^{\circ} \mathrm{C}$, and the maximum fluid temperature is $138.8^{\circ} \mathrm{C}$. If $\mathrm{BeO}$ is used, the projected junction temperature is $143.0^{\circ} \mathrm{C}$, and the maximum fluid temperature is $137.5^{\circ} \mathrm{C}$. 


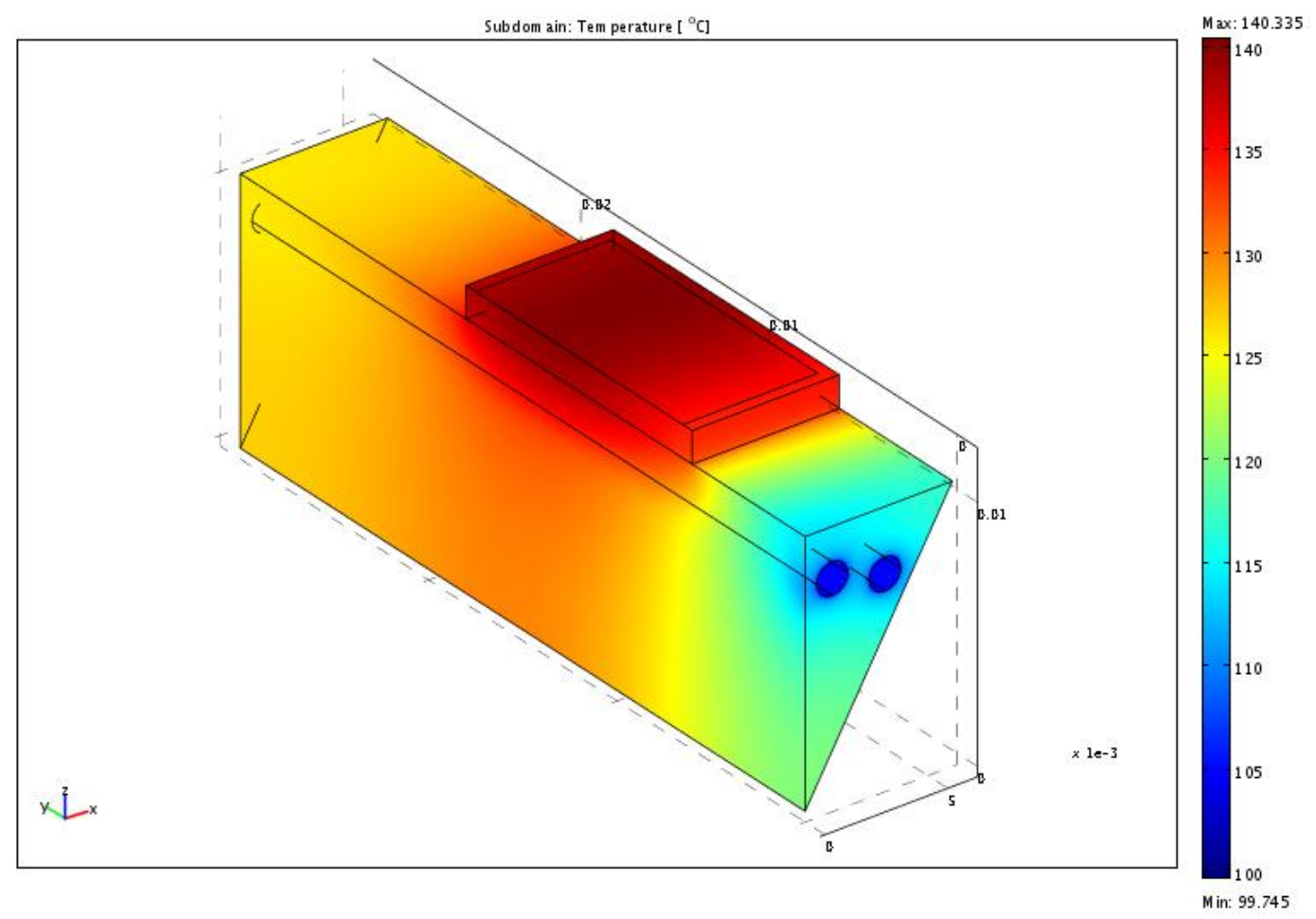

Fig. 13. Temperature distributions for Design 1 with a load of $55 \mathrm{~W}$.

In each case using different ceramic materials, the maximum fluid temperature exceeded the boiling point with the load resulting from four switches. Therefore, no FEA was run using three switches, as the increased load would increase both maximum junction temperature and fluid temperature.

Variations in the WEG mixture were investigated briefly to see if a temperature decrease would result from increasing the thermal conductivity of the solution. Solutions of 60/40 and 70/30 WEG were modeled. The maximum fluid temperatures did decrease but only by about a degree Celsius for each $10 \%$ reduction in EG. Unfortunately the boiling points also readjusted for the new mix ratios. The boiling points also dropped by about a degree Celsius for each $10 \%$ reduction in EG; therefore, the relative difference between maximum fluid temperature and allowable boiling points was constant. Thus, no noticeable benefit was obtained by altering the fluid mixture from 50/50 WEG.

\subsection{THERMAL PERFORMANCE OF DESIGN 2 WITH FLOW THROUGH FOUR HOLES FILLED WITH A POROUS METALLIC FOAM INSERT, 5.4 MM DIAMETER}

Other options were explored because Design 1 resulted in a maximum fluid temperature that exceeded the boiling point of WEG. In order to enhance the thermal conductivity of the fluid, metal foam additions to the flow section were explored. The addition of a thermal enhancer, such as aluminum foam or copper foam, into the flow channels provided a greater surface area within the flow channel to remove the waste heat more efficiently. This material has a much higher structural integrity than other types of microstructures and provided a simple means of manufacture. Figure 14 shows the design geometry with four holes; each would be filled with either a copper foam or aluminum foam insert. The section in the rectangle is the symmetric section that is modeled. Fewer holes are required because more heat can be removed with the addition of the foam. 


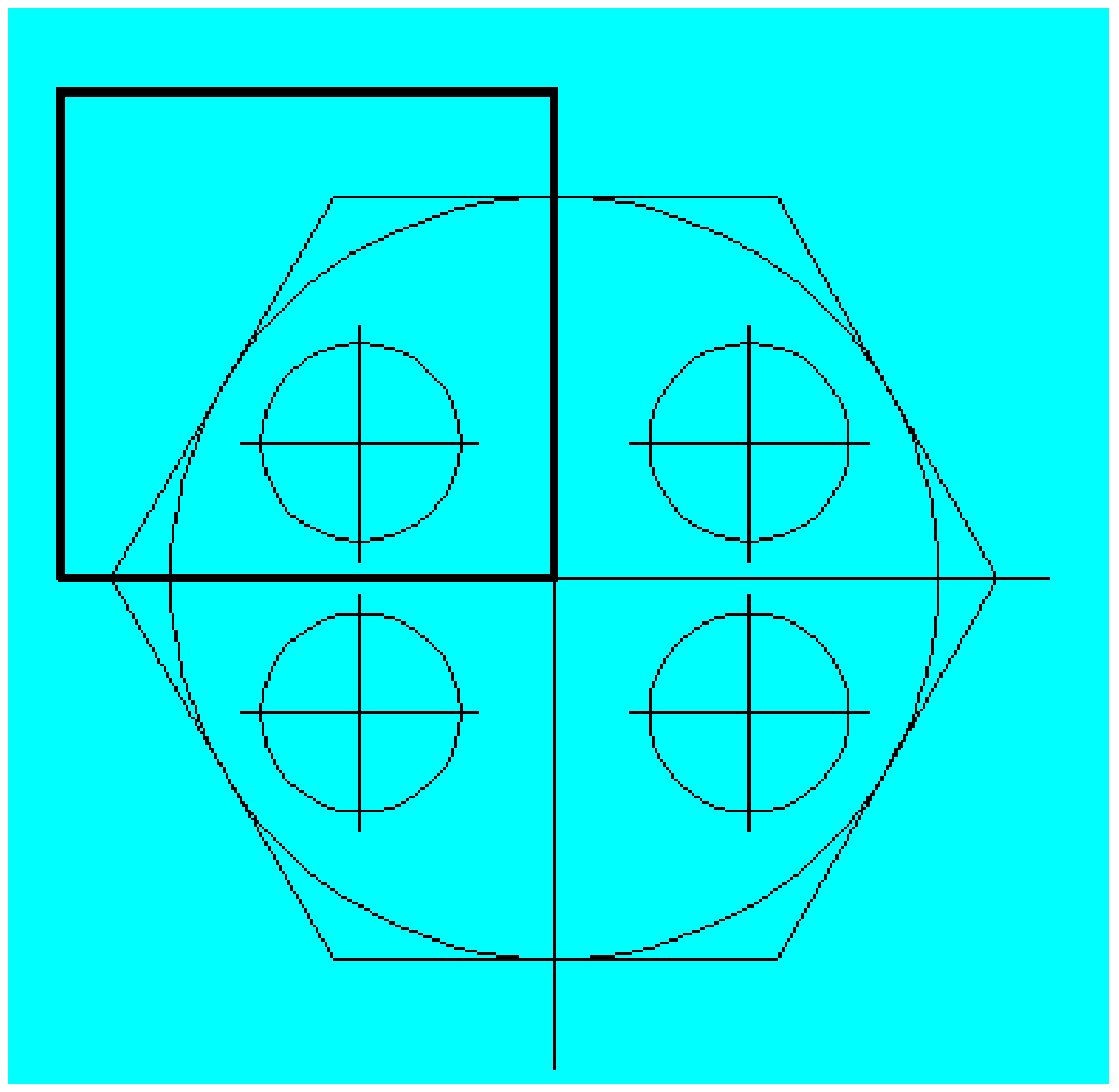

Fig. 14. Sketch of Design 2 with four flow channels.

The properties for the flow channel must be adjusted to reflect the addition of the metallic foam. Also, the velocity of the inlet must be calculated for an effective area because the metal foam matrix blocks some of the inlet area. Table 6 shows the parameters used for the both the copper foam and aluminum foam inserts. The inlet conditions correspond to an inverter flow rate of $2.5 \mathrm{GPM}$ at a temperature of $105^{\circ} \mathrm{C}$.

Table 6. Properties of flow channel with copper foam and aluminum foam insert

\begin{tabular}{|c|c|c|c|c|}
\hline Material & Thermal conductivity & Density & $\begin{array}{l}\text { Specific } \\
\text { hHeat }\end{array}$ & Porosity \\
\hline & W/m, K & $\mathrm{kg} / \mathrm{m} 3$ & $\mathrm{~J} / \mathrm{kg}, \mathrm{K}$ & \\
\hline $\begin{array}{c}50 / 50 \text { mixture with copper } \\
\text { foam }\end{array}$ & 14 & 1775 & 2101 & 0.9 \\
\hline $\begin{array}{l}\text { 50/50 mixture with } \\
\text { aluminum foam }\end{array}$ & 7.2 & 1175 & 3095 & 0.89 \\
\hline
\end{tabular}

The thermal conductivity is an effective thermal conductivity based on correlations by Calmidi and Mahajan [5]. Note that no viscosity was used because the flow field was assumed to be plug flow. This 
assumption is valid based on Darcy's Law for flow through porous media. In short, the metal matrix prohibits boundary layer formation along the walls of the channel which results in plug-type flow.

In Fig. 15, the maximum fluid temperature is $119^{\circ} \mathrm{C}$ and the maximum projected junction is $126.5^{\circ} \mathrm{C}$ when AlN is used with copper foam added to the flow channel and four switches.

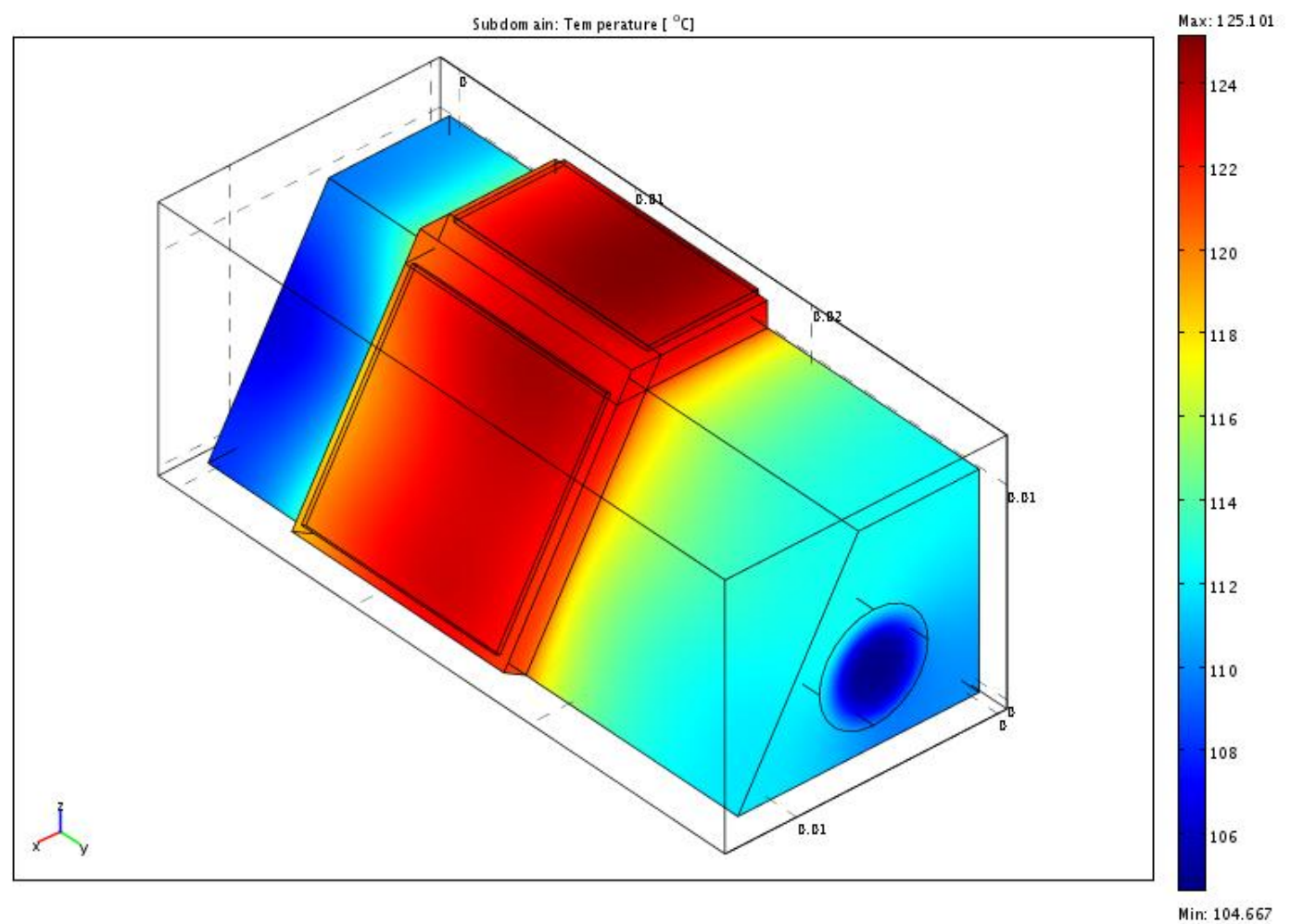

Fig. 15. Temperature distributions in Design 2 with copper foam insert.

If $\mathrm{BeO}$ is used, the maximum junction temperature is $127.6^{\circ} \mathrm{C}$ and the maximum fluid temperature is $119.4^{\circ} \mathrm{C}$. When $\mathrm{Al}_{2} \mathrm{O}_{3}$ is used, the maximum junction temperature is $167.5^{\circ} \mathrm{C}$, and the maximum fluid temperature is $126.6^{\circ} \mathrm{C}$. If $\mathrm{SiC}$ is used, the maximum junction temperature is $128.2^{\circ} \mathrm{C}$ and the maximum fluid temperature is $119.8^{\circ} \mathrm{C}$.

When the aluminum foam is added to the flow channel and four switches are used, the maximum projected junction temperature of $\mathrm{AlN}$ is $129.3^{\circ} \mathrm{C}$ and the maximum fluid temperature is $122.7^{\circ} \mathrm{C}$. If $\mathrm{BeO}$ is used, the maximum junction temperature is $130.6^{\circ} \mathrm{C}$ and the maximum fluid temperature is $123.1^{\circ} \mathrm{C}$. When $\mathrm{Al}_{2} \mathrm{O}_{3}$ is used, the maximum junction temperature is $171.5^{\circ} \mathrm{C}$ and the maximum fluid temperature is $133.4^{\circ} \mathrm{C}$. If $\mathrm{SiC}$ is used, the maximum junction temperature is $131.9^{\circ} \mathrm{C}$ and the maximum fluid temperature is $123.7^{\circ} \mathrm{C}$.

For a design with three chips using AlN, the maximum projected junction temperature is $133.8^{\circ} \mathrm{C}$ and the maximum fluid temperature is $123.7^{\circ} \mathrm{C}$. This design could use three or four switches based on the thermal analysis for the higher-thermal-conductivity ceramics. If three switches were used, the minimum radiator pressure should be 15 psig to allow for a margin of safety. 


\subsection{THERMAL PERFORMANCE OF DESIGN 3 WITH FLOW THROUGH ONE FLOW CHANNEL FILLED WITH A POROUS METALLIC FOAM INSERT, 9 MM DIAMETER}

Figure 16 shows the third design. The flow channel in the center is $9 \mathrm{~mm}$ in diameter and is filled with a metallic foam insert. The triangular section represents the modeled (one-twelfth) symmetric section. The material properties were the same as for the previous case. The inlet conditions corresponded to a flow rate of $2.5 \mathrm{GPM}$ for the whole inverter at a temperature of $105^{\circ} \mathrm{C}$.

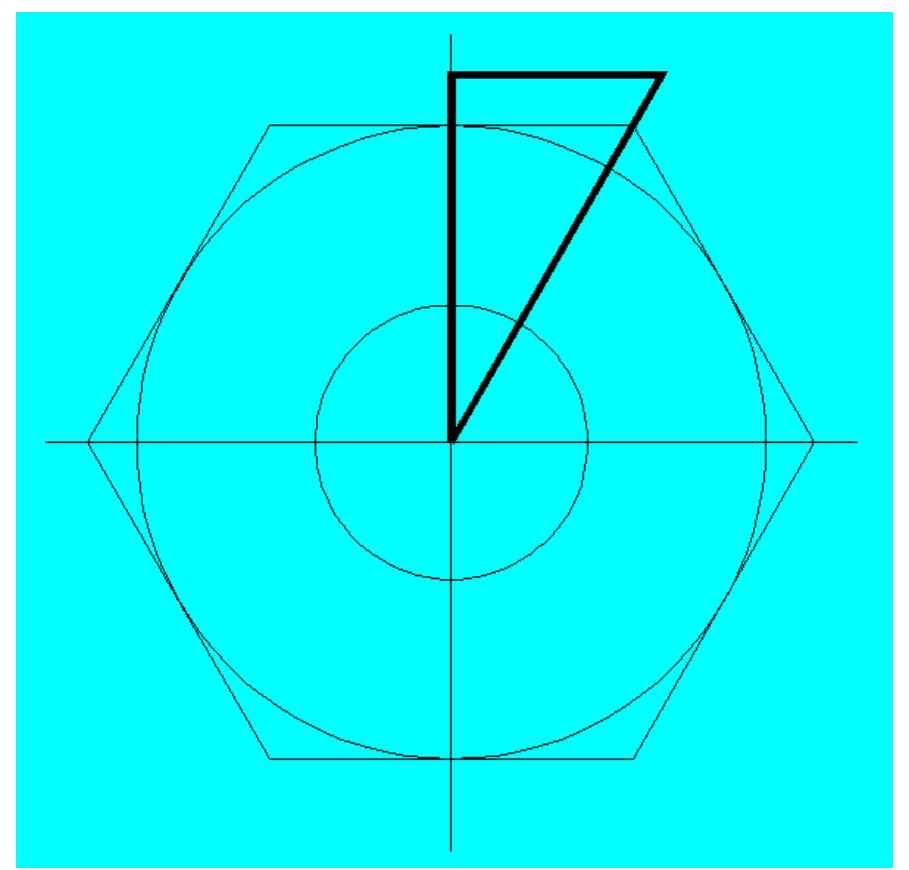

Fig. 16. Sketch of Design 3 with one flow channel.

Figure 17 shows the temperature distribution in Design 3 with a copper foam insert. Decreasing the number of flow channels to one allows for much simpler construction and manufacturing. Using a total of four switches, the maximum junction temperature for $\mathrm{AlN}$ is $137.3^{\circ} \mathrm{C}$ and the maximum fluid temperature is $120.5^{\circ} \mathrm{C}$. When $\mathrm{BeO}$ is used, the maximum junction temperature is $138.8^{\circ} \mathrm{C}$ and the maximum fluid temperature is $120.6^{\circ} \mathrm{C}$. If $\mathrm{Al}_{2} \mathrm{O}_{3}$ is used, the maximum junction temperature is $219.5^{\circ} \mathrm{C}$ and the maximum fluid temperature is $121.4^{\circ} \mathrm{C}$. If $\mathrm{SiC}$ is used, the maximum junction temperature is $140.9^{\circ} \mathrm{C}$ and the maximum fluid temperature is $120.7^{\circ} \mathrm{C}$. For three switches using AlN, the temperatures remain within the performance criteria with a maximum junction of $147.9^{\circ} \mathrm{C}$ and a maximum fluid temperature of $125.6^{\circ} \mathrm{C}$. 


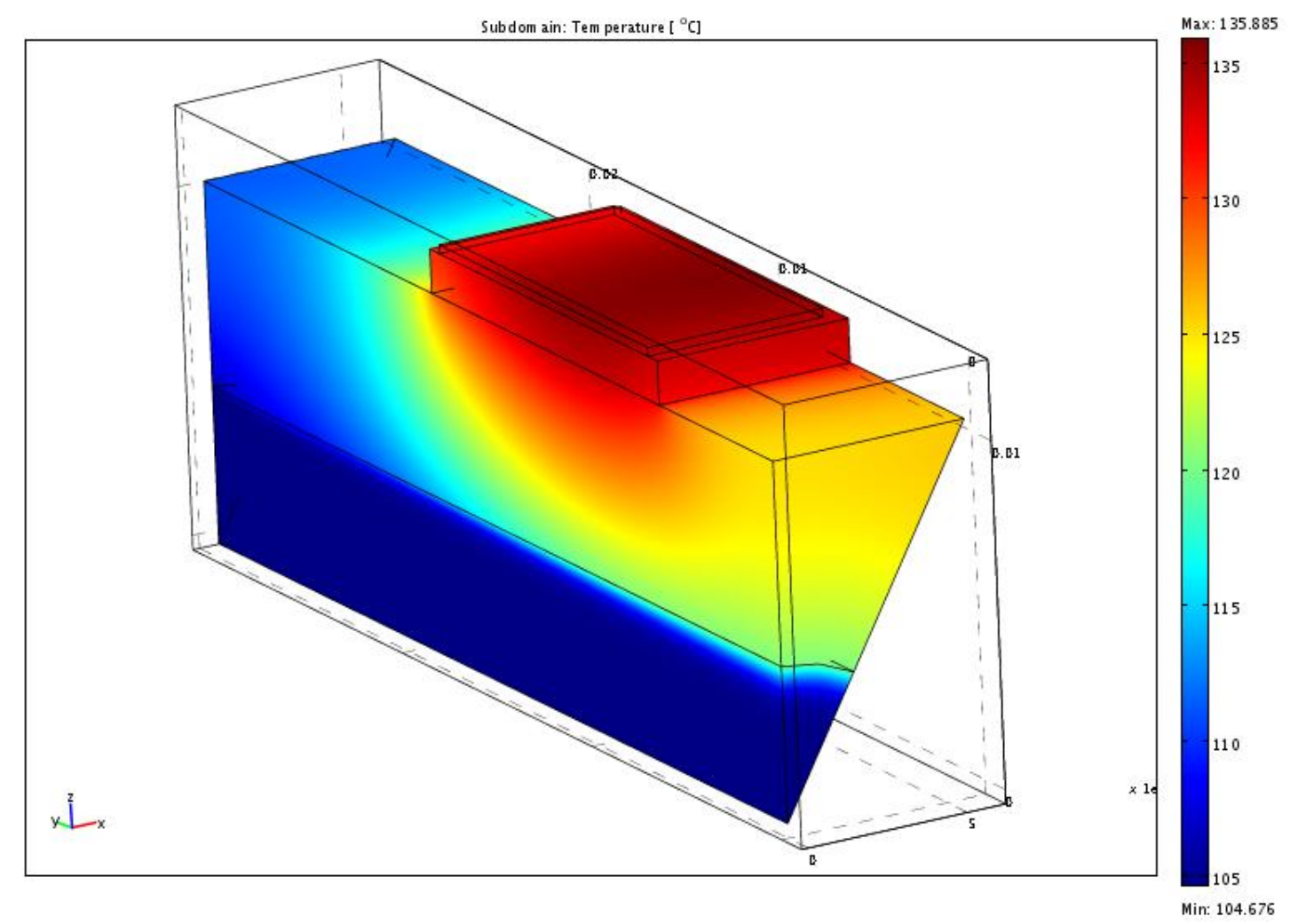

Fig. 17. Temperature distributions in Design 3 with copper foam insert.

Using a total of four switches and adding aluminum foam to the flow channel, the maximum junction temperature for $\mathrm{AlN}$ is $142.3^{\circ} \mathrm{C}$, and the maximum fluid temperature is $126.1^{\circ} \mathrm{C}$. When $\mathrm{BeO}$ is used, the maximum junction temperature is $143.8^{\circ} \mathrm{C}$ and the maximum fluid temperature is $126.3^{\circ} \mathrm{C}$. If $\mathrm{Al}_{2} \mathrm{O}_{3}$ is used, the maximum junction temperature is $224.4^{\circ} \mathrm{C}$ and the maximum fluid temperature is $127.9^{\circ} \mathrm{C}$. If $\mathrm{SiC}$ is used, the maximum junction temperature is $145.9^{\circ} \mathrm{C}$ and the maximum fluid temperature is $126.4^{\circ} \mathrm{C}$.

Again, the maximum temperatures for this design would decrease as the diameter of the copper foam increased. This increase in diameter would need to be contrasted against the cost and structural integrity of the ceramic during thermal cycling. If fewer switches were used in either the copper or aluminum foam design containing a single flow channel, then the system pressure would need to be maintained at around 16 psig to ensure that boiling would not occur.

The foam structure adds another benefit in that it can restrict bubble growth in the event of boiling. In an open-channel design, bubbles can grow to the point of blocking flow. Furthermore, as a bubble develops on the wall it creates a local hot spot that could be detrimental to a chip. The foam limits the bubble growth size to roughly the pore size of the foam. Thus if boiling were to occur, which the models do not predict, it could neither significantly block the flow nor create a large hot spot near the wall. 


\subsection{THERMAL PERFORMANCE OF DESIGN 4 WITH FLOW THROUGH A ANNULAR FLOW CHANNEL FILLED WITH A POROUS METALLIC FOAM INSERT}

Based on careful examination of the previous designs for all materials, a lower-cost option for the higherthermal-conductivity materials ( $\mathrm{AlN}, \mathrm{BeO}$, and $\mathrm{SiC}$ ) needed to be explored. Even though the thermal performance of those ceramics is far superior to that of $\mathrm{Al}_{2} \mathrm{O}_{3}$, substrates made of these materials would cost almost as much as the whole inverter at the current OEM's cost target, so their consideration was discontinued. Additionally, concern was beginning to mount over the chemical compatibility of AlN with WEG (and therefore the potential for erosion of AlN) as shown in Fig. 5. That lent a further rationale for considering $\mathrm{Al}_{2} \mathrm{O}_{3}$ instead because it is chemically inert against WEG. In another design iteration to improve the thermal performance of a substrate made with $\mathrm{Al}_{2} \mathrm{O}_{3}$, an annular flow channel with aluminum foam was modeled. Figure 18 is a sketch of this geometry.

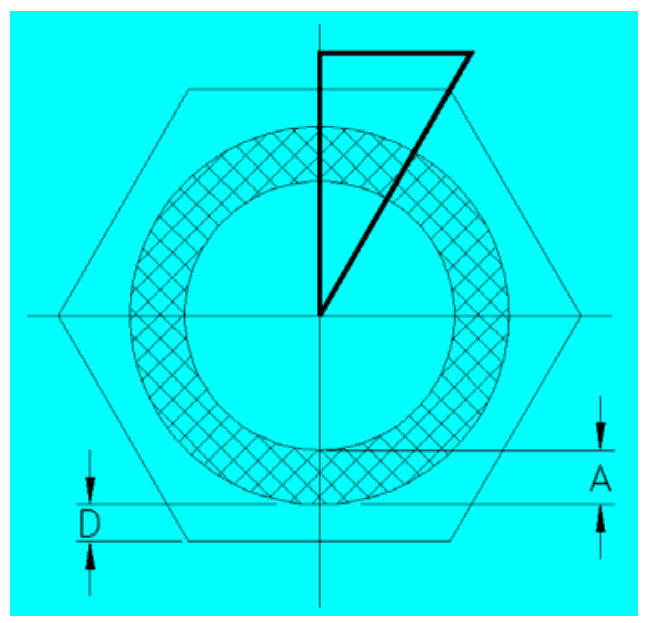

Fig. 18. Schematic of annular geometry.

In this geometry the minimum distance from the face to the flow channel $\mathrm{D}$ can be smaller than in the previous models. This smaller distance is a result of an increase in local velocities created by the annular shape. For the model, D was $3.4 \mathrm{~mm}$ and A, the annulus thickness, was $5 \mathrm{~mm}$. Five millimeters was chosen based on the general dimensions of the aluminum foam matrix. If the annulus thickness was too thin, the foam would not have any structural integrity. The radii were determined based on these parameters and the hexagon face width. The inlet velocity was determined based on a constant inverter flow rate of 2.5 GPM. Figure 19 shows the maximum temperatures for this design. 


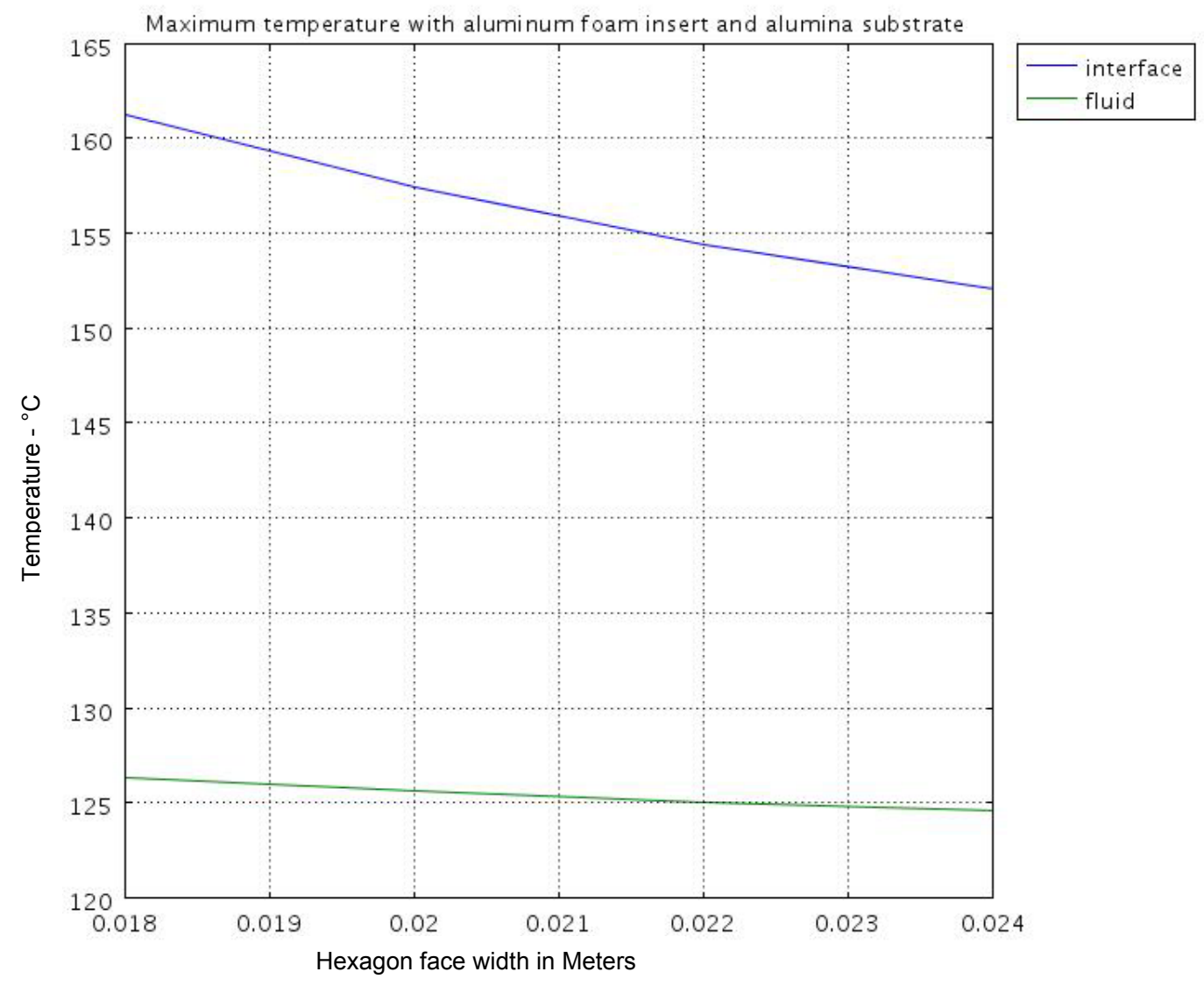

Fig. 19. Maximum interface and fluid temperatures for annular flow channel geometry with aluminum foam, $D=3.4 \mathrm{~mm}$ and $\mathrm{A}=5 \mathrm{~mm}$.

At a face width of $18 \mathrm{~mm}$, the temperatures are within the maximum limits of the design. This performance is a considerable improvement over the $\mathrm{Al}_{2} \mathrm{O}_{3}$ single flow channel in Design 3. To increase the reliability of the power electronics, the hexagon face could be increased more.

The probability of survival (POS) of the $\mathrm{Al}_{2} \mathrm{O}_{3}$ substrate subjected to the conditions shown in Fig. 20 was determined by performing an established two-step analysis. First, the thermo-mechanical stress state within the $\mathrm{Al}_{2} \mathrm{O}_{3}$ substrate was determined using FEA (ANSYS, Canonsburg, PA). A one-twelfth symmetry was utilized, as shown in Fig. 21. The thermal conductivities, coefficients of thermal expansions, elastic moduli, and Poisson's ratios of the $\mathrm{Al}_{2} \mathrm{O}_{3}$, copper (directly bonded to the $\mathrm{Al}_{2} \mathrm{O}_{3}$ ), solder, and silicon chip were taken into account. The solder was allowed to yield but the other three materials in the model remained linearly elastic (see Fig. 22). Heat generation in the silicon chip (55 W) was accounted for. At a face width of $24 \mathrm{~mm}$, which is twice the nominal width of $12 \mathrm{~mm}$ using higherthermal-conductivity materials, the maximum interface temperature was around $152^{\circ} \mathrm{C}$ and the maximum fluid temperature was below $125^{\circ} \mathrm{C}$ (see Fig. 23). Again these temperatures meet the maximum limits of the design parameters. 


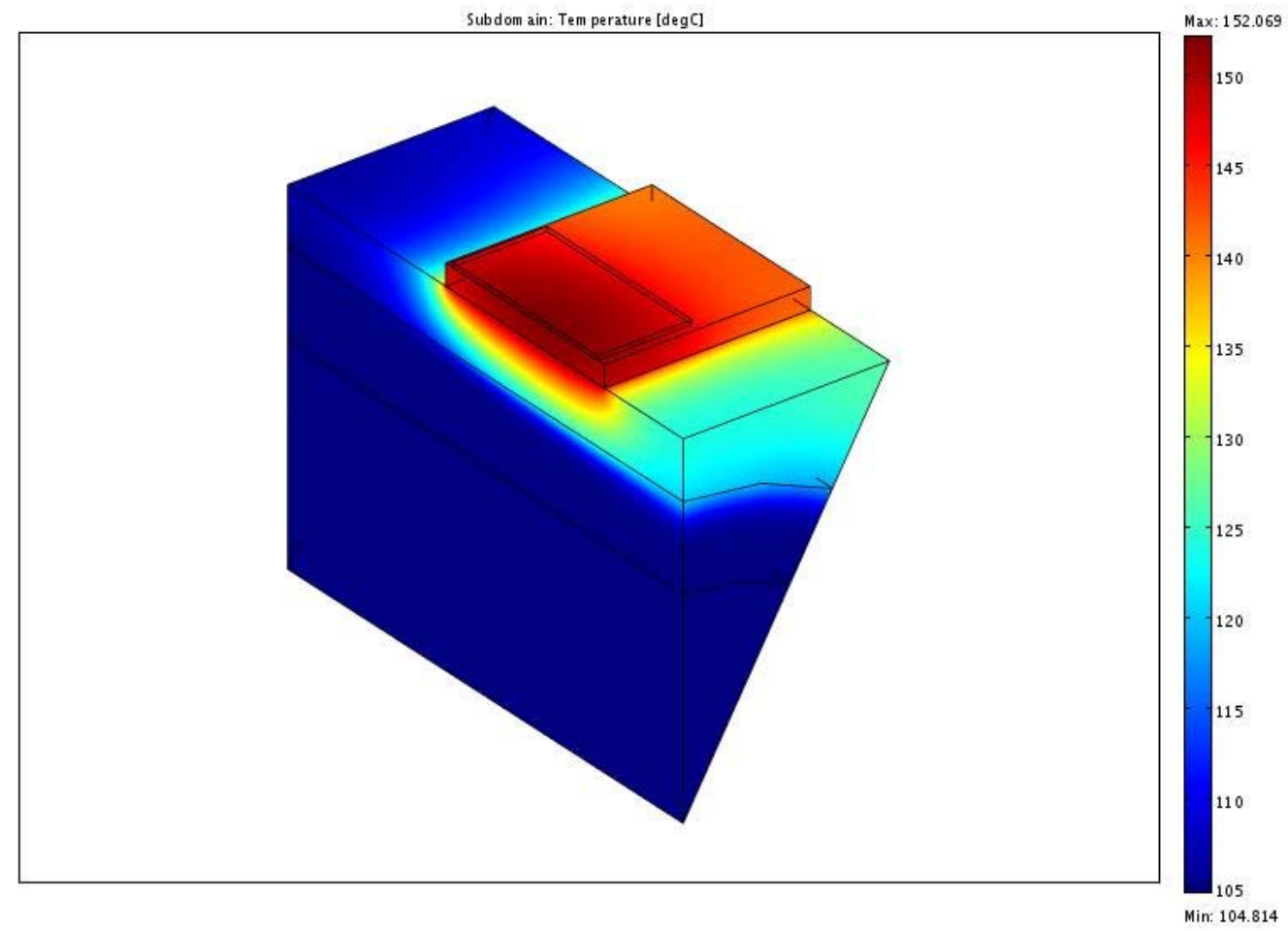

Fig. 20. Temperature distribution in Design 4, $24 \mathrm{~mm}$ face width alumina ceramic with annular flow channel geometry.

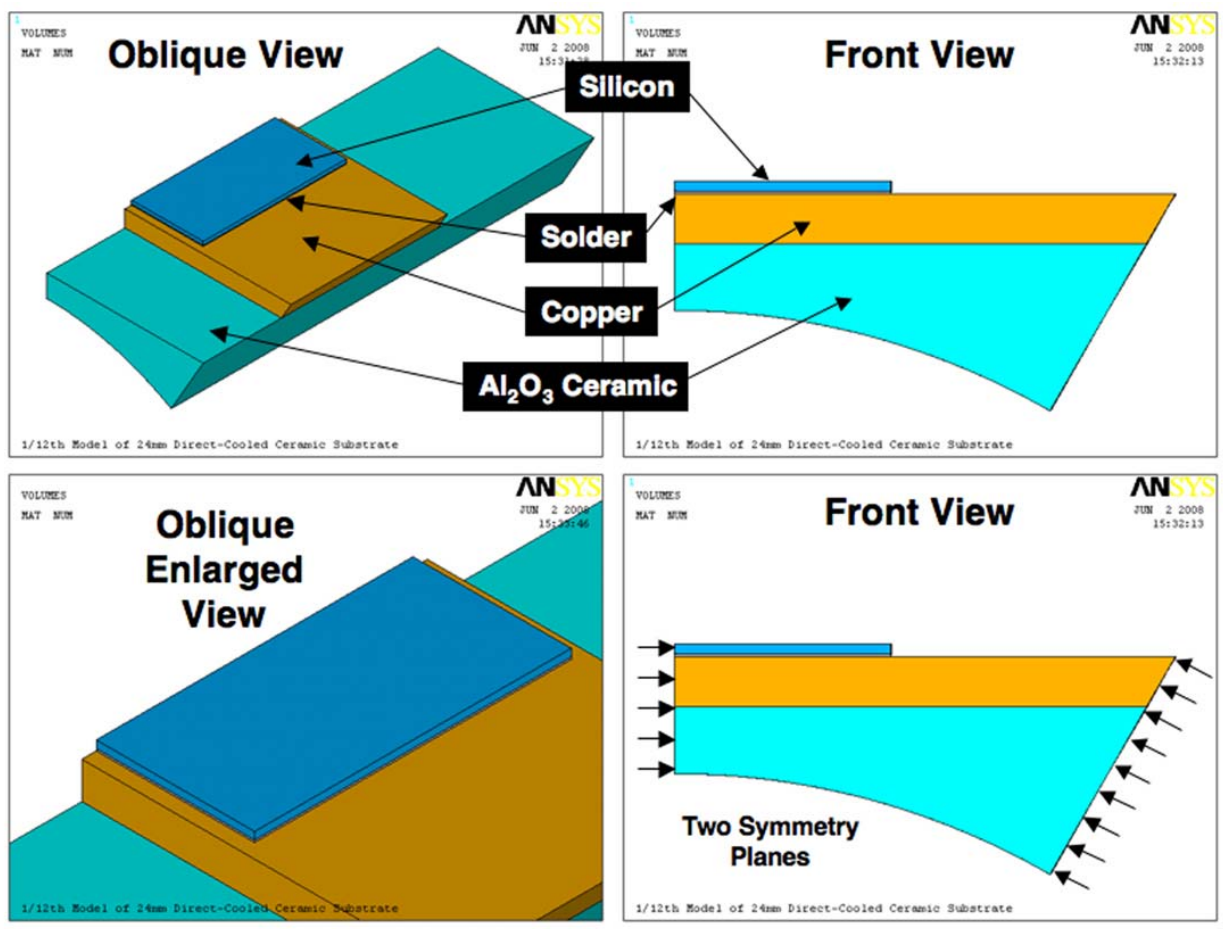

Fig. 21. One-twelfth thermo-mechanical FEA model of Design 4, $24 \mathrm{~mm}$ face width alumina ceramic with annular flow channel geometry. 


\begin{tabular}{|c|c|c|c|c|c|}
\hline Material & $\begin{array}{c}\mathrm{E} \\
(\mathrm{GPa})\end{array}$ & $\begin{array}{c}\text { Poisson's } \\
\text { Ratio }\end{array}$ & $\begin{array}{c}\mathrm{CTE} \\
\left(\mathrm{ppm}{ }^{\circ}{ }^{\circ} \mathrm{C}\right)\end{array}$ & $\begin{array}{c}\kappa \\
(\mathrm{W} / \mathrm{mK})\end{array}$ & $\begin{array}{c}\text { Yield } \\
\text { Strength } \\
(\mathrm{MPa})\end{array}$ \\
\hline $\mathrm{Al}_{2} \mathrm{O}_{3}$ & 360 & 0.24 & 8 & 25 & \\
\hline Copper & 117 & 0.30 & 17 & 400 & 138 \\
\hline Solder & 12.5 & 0.36 & 26 & 15 & 22 \\
\hline Silicon & 130 & 0.28 & 4 & 130 & \\
\hline
\end{tabular}

Fig. 22. Material properties used in the thermo-mechanical FEA model.
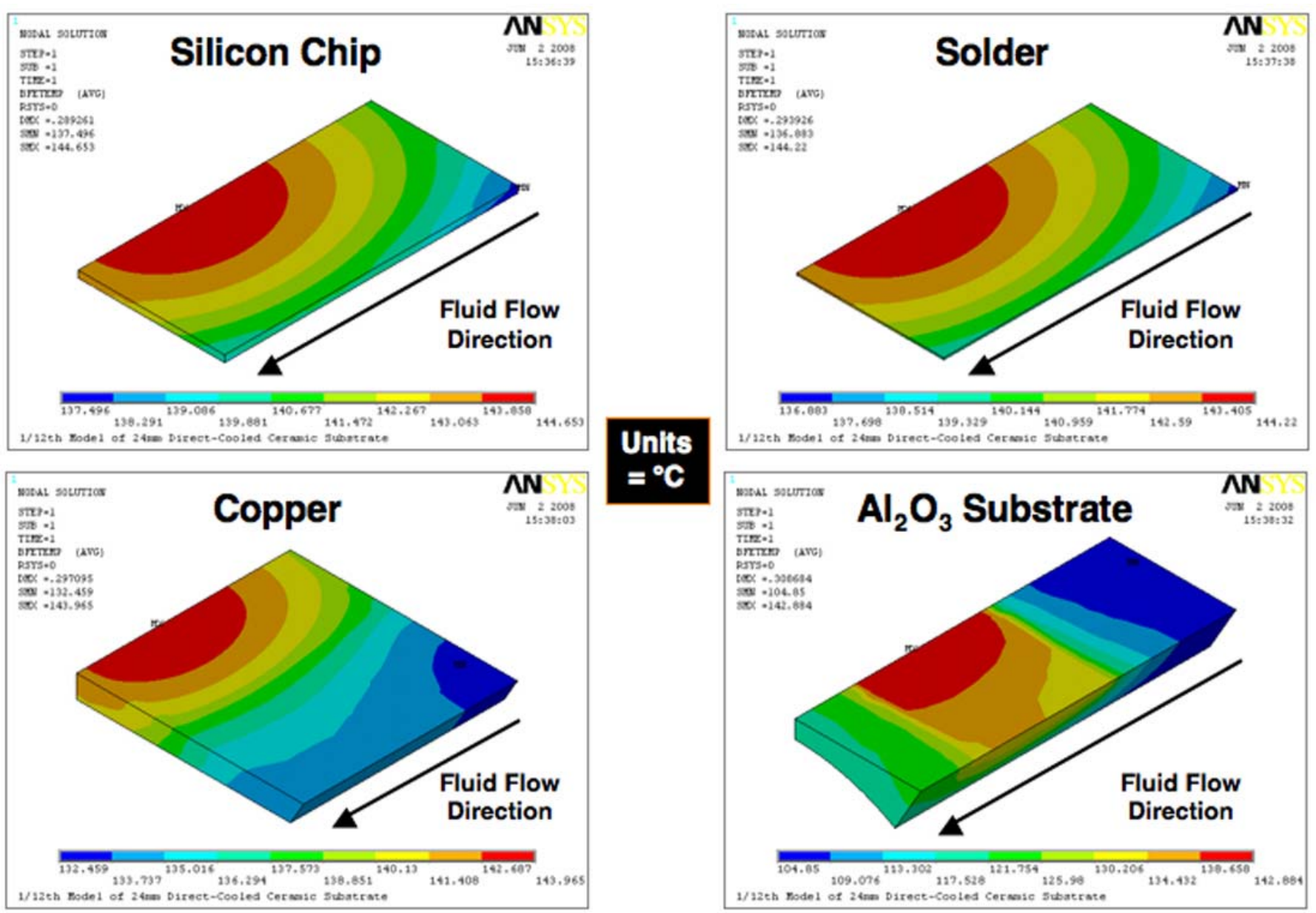

Fig. 23. Temperature profiles in each of the four subcomponents. 
The magnitude of the first-principles tensile stresses and their field dictate the POS of a ceramic component, so that the (thermal-induced) stress field was determined and is shown in Fig. 24. The POS was determined by incorporating both of the two-parameter Weibull strength distributions for $\mathrm{Al}_{2} \mathrm{O}_{3}$ limited by both volume- and surface-type flaws. In this analysis, the Weibull moduli of both were taken to be 15 , and the scaling parameters were $500 \mathrm{MPa} \cdot \mathrm{mm}^{3 / \mathrm{m}}$ for volume-based analysis and $500 \mathrm{MPa} \cdot \mathrm{mm}^{2 / \mathrm{m}}$ for surface-based analysis. The combination of the first-principles tensile stress field and those Weibull parameters occurred using a FEA post-processing software called Ceramic Analysis and Reliability Evaluation of Structures (CARES [Connecticut Reserve Technologies, Gates Mills, OH]).

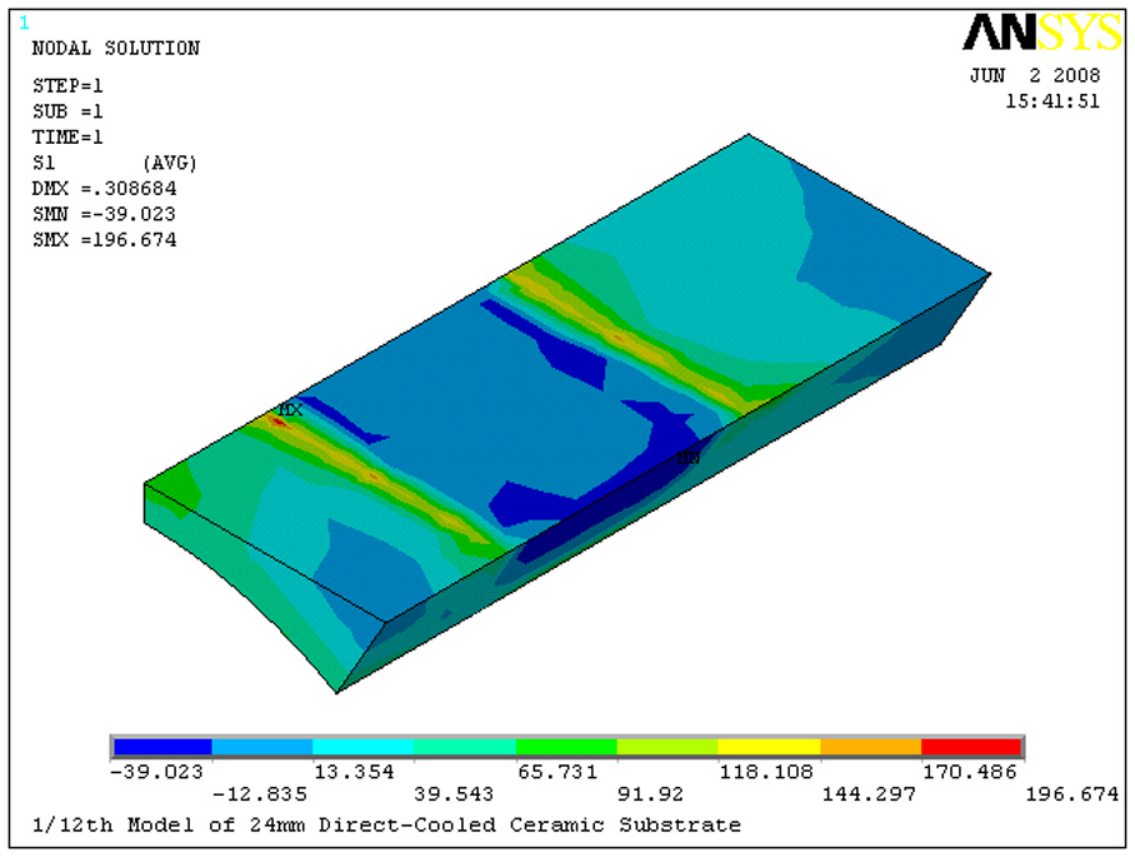

Fig. 24. First-principles stresses in the $\mathrm{Al}_{2} \mathrm{O}_{3}$ ceramic substrate (Design 4).

The CARES analysis showed that the maximum first-principles tensile stresses from thermal loading were low and easily within the mechanical capability of the $\mathrm{Al}_{2} \mathrm{O}_{3}$ ceramic. Its resulting POS analysis showed that 999,992 out of 1,000,000 hexagonal structures (99.9992\%) of Design 4 should sustain the imposed thermo-mechanical stresses without mechanical failure. Further optimization of this geometry could be explored to decrease the face-to-radius distance and increase the POS, but this model shows that a candidate $\mathrm{Al}_{2} \mathrm{O}_{3}$ ceramic geometry is actually quite viable in Design 4.

This design adds some other benefits. A common product with aluminum foam is a pipe with foam bonded onto the outer surface. In Design 4, an aluminum pipe with foam could be pressed into a larger hole to form the annulus. The aluminum pipe ends would have to be brazed closed to prevent a fluid bypass. However, the overall effect would reduce the weight of the substrate and should keep the cost lower because less $\mathrm{Al}_{2} \mathrm{O}_{3}$ is needed to make the part compared with a solid core. 


\subsection{THERMAL PERFORMANCE OF DESIGN 5 WITH FLOW THROUGH FOUR HOLES FILLED WITH A POROUS METALLIC FOAM INSERT, 9.8 MM DIAMETER}

To provide another design option with $\mathrm{Al}_{2} \mathrm{O}_{3}$, a four-hole design was explored. Again the face width had to be increased to reduce the operating temperatures to the design limits. In this design process, the size of the flow channel, which is filled with aluminum foam, and the hole center location were varied to find an optimum design. In the final design iteration, the center of the hole was offset from the center of the chip to provide the coolest chip temperatures. The resulting temperatures proved that the offset dimension was critical for this design to meet the performance criteria. The highlighted section in Fig. 25 represents the (one-fourth) symmetric section of the model used for FEA.

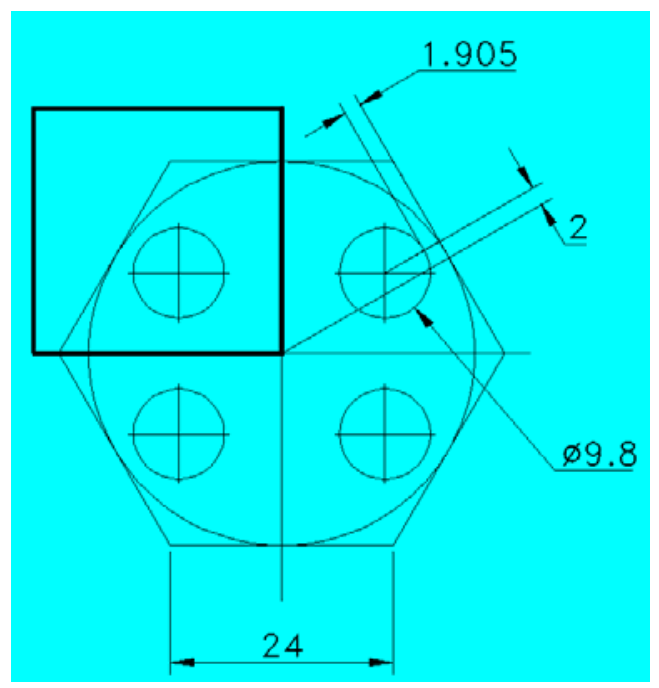

Fig. 25. Design 5 with four offset 9.8-mm-diameter flow channels.

The FEA run on this model used a top silicon chip heat generation of $37 \mathrm{~W}$ to represent a diode, and a side silicon chip heat generation of $55 \mathrm{~W}$ to represent an IGBT. Figure 26 represents the chip and fluid temperatures at various offset dimensions.

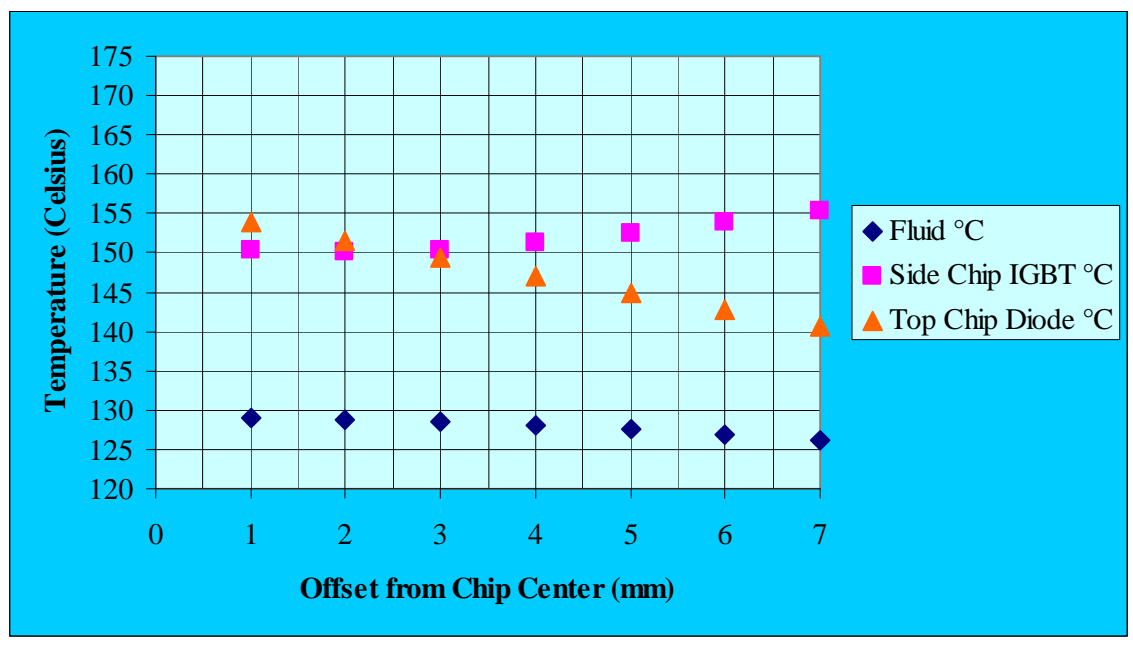

Fig. 26. Critical temperatures for 9.8-mm-diameter coolant channel. 
Figure 27 represents the temperature distribution of Design 5. This design contains a 24-mm face with a $\mathrm{Al}_{2} \mathrm{O}_{3}$ ceramic containing aluminum foam with the flow channel offset $2 \mathrm{~mm}$ from the chip center.

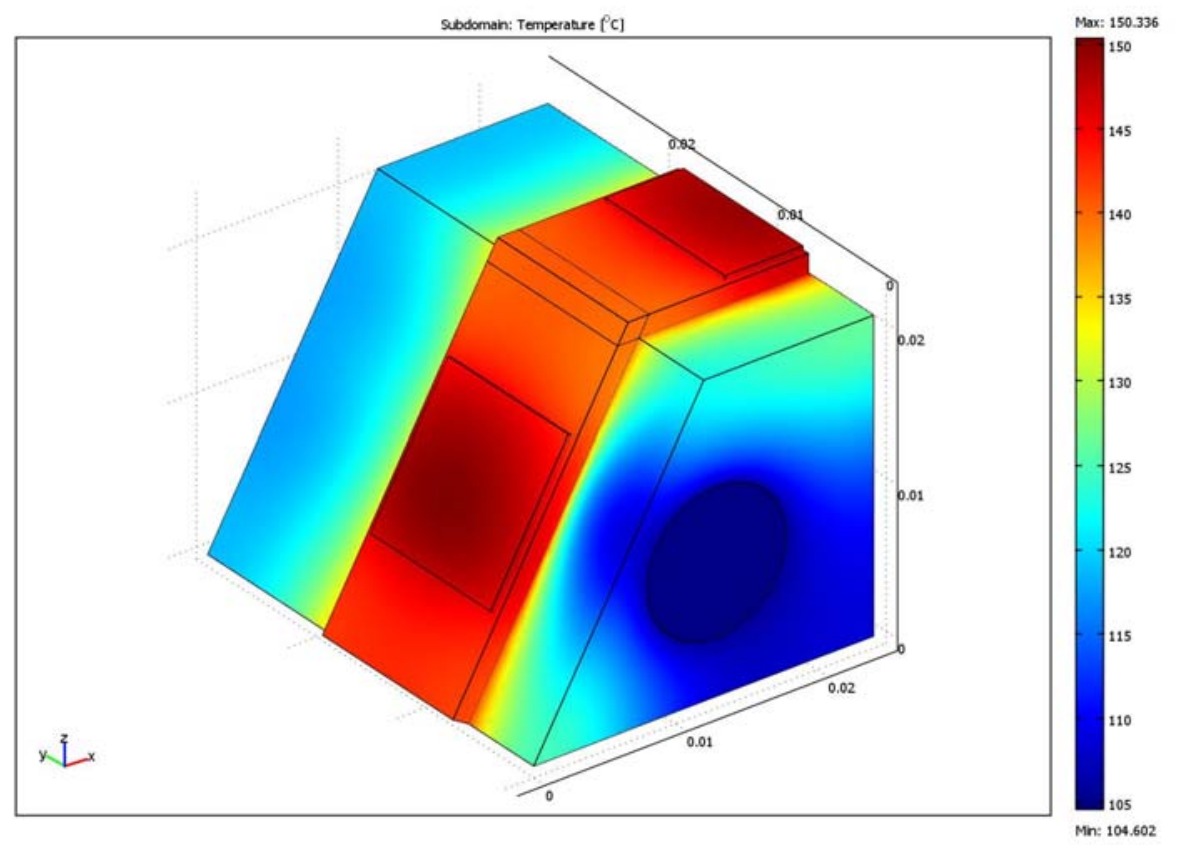

Fig. 27. Temperature distribution of Design 5 containing four coolant channels with each channel offset $2 \mathrm{~mm}$ from chip center.

Another ceramic POS analysis study was conducted using the information portrayed in Figs. 25-27. A one-fourth model of Design 5 was constructed in ANSYS and is shown in Fig. 28. Copper and solder dimensions were the same as those shown in Fig. 21 and are included in Fig. 28. The IGBT (left in Fig. 28) generated $55 \mathrm{~W}$ and the diode (top in Fig. 28) generated $37 \mathrm{~W}$. The maximum chip temperature is $153^{\circ} \mathrm{C}$ and the maximum fluid temperature is below $125^{\circ} \mathrm{C}$, and those meet the design temperature constraints (see Fig. 29). Again these temperatures met the maximum limits of the design parameters. The same properties shown in Fig. 22 were again used in this analysis of Design 5. The resulting firstprinciples tensile stress field within the ceramic substrate is shown in Fig. 30.

Using the same Weibull parameters as above, CARES analysis showed that the maximum first-principles tensile stresses from thermal loading were low and easily within the mechanical capability of the $\mathrm{Al}_{2} \mathrm{O}_{3}$ ceramic. The POS analysis showed that 999,906 out of 1,000,000 hexagonal structures (99.9906\%) of Design 5 will sustain the imposed thermo-mechanical stresses without mechanical failure. Further optimization of this geometry could be explored to decrease the face-to-radius distance and increase the POS, but this model also shows that a candidate $\mathrm{Al}_{2} \mathrm{O}_{3}$ ceramic geometry is again quite viable in Design 5. 


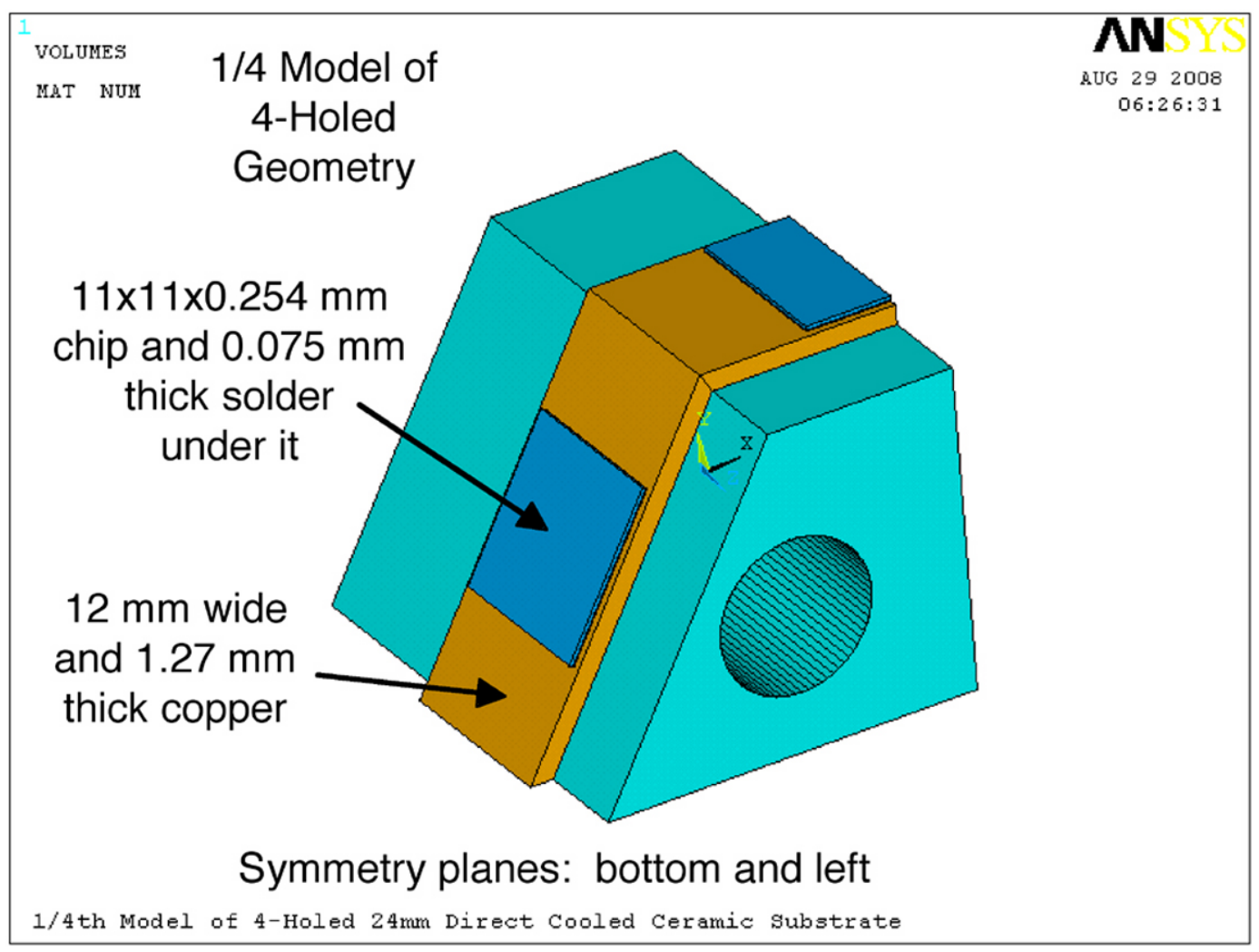

Fig. 28. One-fourth thermo-mechanical FEA model of Design 5 containing four coolant channels with each channel offset $2 \mathrm{~mm}$ from chip center.

\section{Entire (One-Quarter) Model}

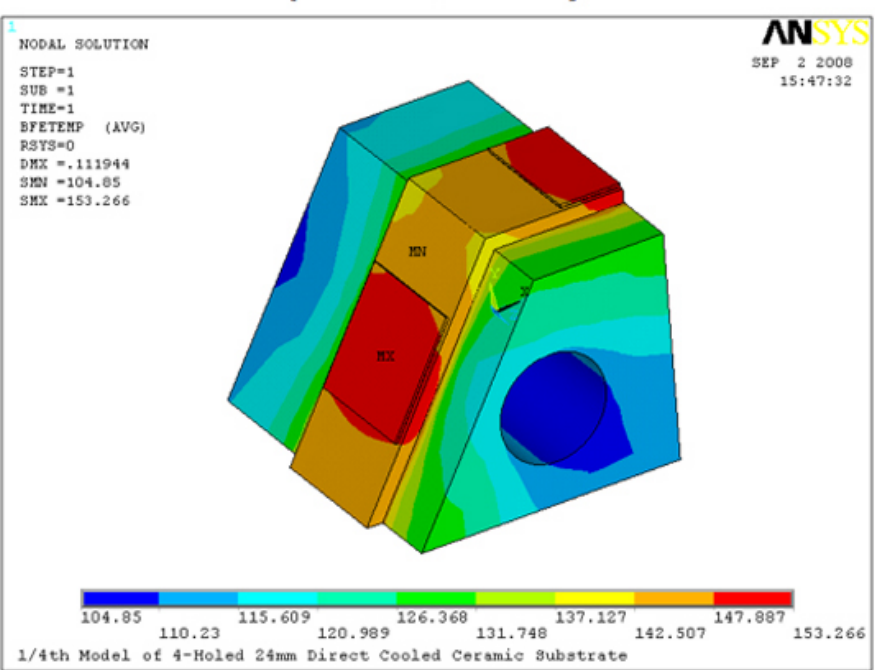

\section{Ceramic Substrate}

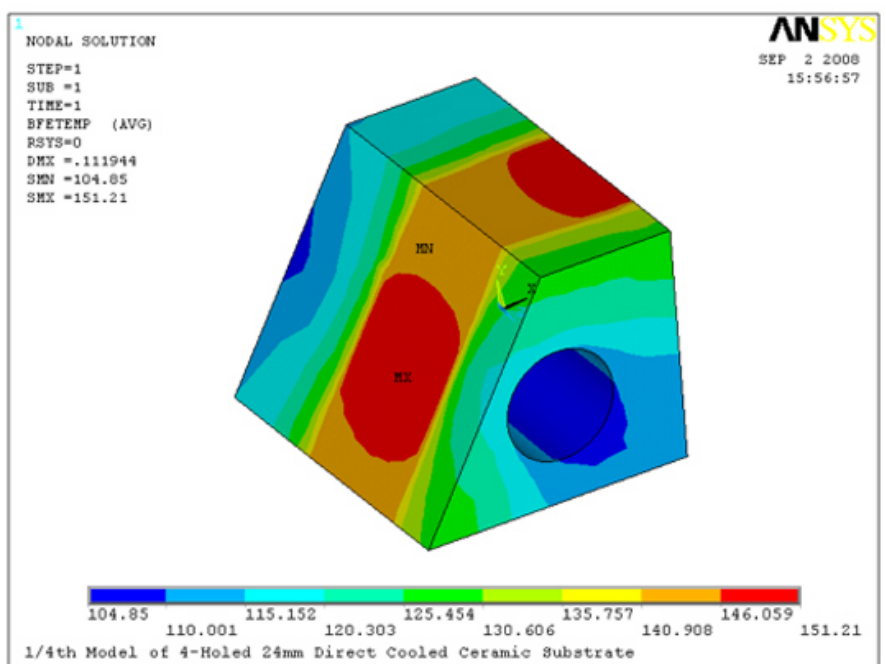

Fig. 29. Temperature profiles in Design 5. 


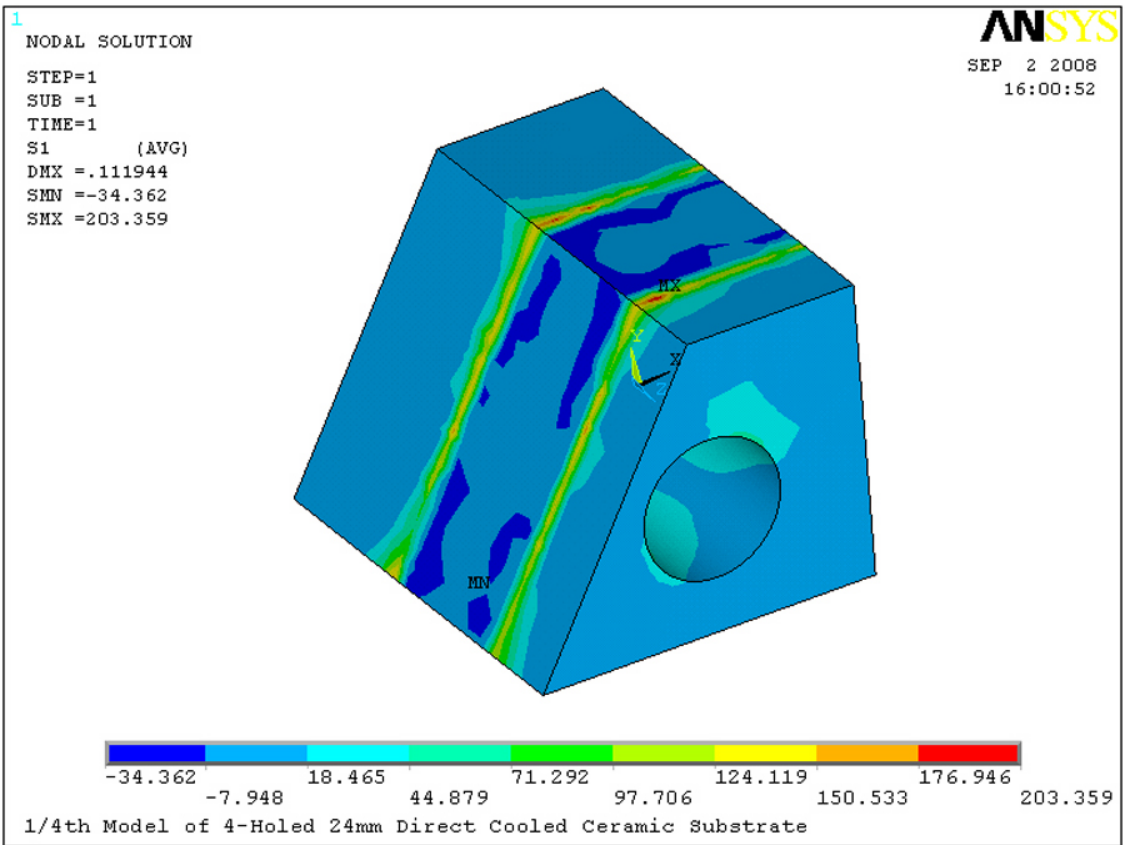

Fig. 30. First-principles stresses in the $\mathrm{Al}_{2} \mathrm{O}_{3}$ ceramic substrate (Design 5). 


\subsection{DESIGN CONCLUSION}

\subsection{DESIGN MATRIX SUMMARY}

A performance matrix and weight system was developed to help evaluate the effectiveness of each design. These design matrix summaries are listed in Tables 7-13. They contain the loads, thermal data resulting from the use of three or four IGBTs, manufacturing variables and trade-offs, and cost to manufacture in quantities of 100,000 pieces. If the thermal results of some designs using four IGBTs were at or above the design criteria limitations, no FEAs were needed using fewer chips. In addition, velocities were determined for each design that exceeded the performance criteria to determine how much flow increase was required to meet the design intent. This increase in velocity was helpful in determining the preferred designs; however, OEMs recommended the volumetric flow rate be maintained at a maximum of 2.5 GPM.

Table 7. Design 1 matrix summary

\begin{tabular}{|c|c|c|c|c|}
\hline Design & \multicolumn{4}{|c|}{1} \\
\hline Description & \multicolumn{4}{|c|}{24 holes $1.27 \mathrm{~mm}$ diameter } \\
\hline Ceramic insulator & AlN & $\mathrm{BeO}$ & Alumina & $\mathrm{SiC}$ \\
\hline \multicolumn{5}{|l|}{ Copper foam (10 ppi, 8\% $\left.\rho_{\text {rel }}\right)$} \\
\hline \multicolumn{5}{|l|}{ Aluminum foam (10 ppi, $\left.8 \% \rho_{\text {rel }}\right)$} \\
\hline Load (W/switch) & \multicolumn{4}{|c|}{55} \\
\hline \multicolumn{5}{|l|}{ Performance at 2.5 GPM for entire inverter } \\
\hline Max projected junction temperature & 141.7 & 143.0 & 182.9 & 144.7 \\
\hline Max. fluid temperature & 136.5 & 137.5 & 163.0 & 138.8 \\
\hline Pass 1-mm particle & \multicolumn{4}{|c|}{$\sqrt{ }$} \\
\hline Compatible with WEG & & $\sqrt{ }$ & $\sqrt{ }$ & $\sqrt{ }$ \\
\hline \multicolumn{5}{|l|}{ Manufacturability } \\
\hline Smallest feature size (mm) & \multicolumn{4}{|c|}{1.27} \\
\hline Post processing (assembly, machining...) & & & & \\
\hline \multicolumn{5}{|l|}{ Trade-offs to meet design criteria } \\
\hline Required flow rate (GPM) & $>7.25$ & $>7.95$ & Large & $>8.67$ \\
\hline Filter & \multicolumn{4}{|c|}{ no } \\
\hline Cost per ceramic rated from 100,000 pcs. & $\$ 45.87$ & $\$ 19.59$ & $\$ 2.97$ & $\$ 30.25$ \\
\hline \multicolumn{5}{|l|}{ Optimization } \\
\hline Load (W/switch) & \multicolumn{4}{|c|}{$\mathrm{n} / \mathrm{a}$} \\
\hline $150 \mathrm{C}$ - max. projected junction temperature & 0 & 0 & 0 & 0 \\
\hline EG BP @ 16psig - max. fluid temperature & 0 & 0 & 0 & 0 \\
\hline
\end{tabular}


Table 8. Design 2 matrix summary using copper foam

\begin{tabular}{|c|c|c|c|c|}
\hline Design & \multicolumn{4}{|c|}{2} \\
\hline Description & \multicolumn{4}{|c|}{4 holes $5.7 \mathrm{~mm}$ diameter } \\
\hline Ceramic insulator & AlN & $\mathrm{BeO}$ & Alumina & $\mathrm{SiC}$ \\
\hline Copper foam (10 ppi, $\left.8 \% \rho_{\text {rel }}\right)$ & \multicolumn{4}{|c|}{$\sqrt{ }$} \\
\hline Aluminum foam (10 ppi, $\left.8 \% \rho_{\text {rel }}\right)$ & & & & \\
\hline Load (W/switch) & \multicolumn{4}{|c|}{55} \\
\hline \multicolumn{5}{|l|}{ Performance at 2.5 GPM for entire inverter } \\
\hline Max projected junction temperature & 126.5 & 127.6 & 167.5 & 128.8 \\
\hline Max. fluid temperature & 119.0 & 119.4 & 126.6 & 119.8 \\
\hline Pass 1-mm particle & \multicolumn{4}{|c|}{ Probably } \\
\hline Compatible with WEG & & $\sqrt{ }$ & $\sqrt{ }$ & $\sqrt{ }$ \\
\hline \multicolumn{5}{|l|}{ Manufacturability } \\
\hline Smallest feature size (mm) & \multicolumn{4}{|c|}{5.7} \\
\hline Post processing (assembly, machining...) & \multirow{2}{*}{\multicolumn{4}{|c|}{ Foam insert }} \\
\hline Trade-offs to meet design criteria & & & & \\
\hline Required flow rate (GPM) & 2.5 & 2.5 & 3.88 & 2.5 \\
\hline Filter & \multicolumn{4}{|c|}{ Possibly } \\
\hline Cost per ceramic rated from 100,000 pcs. & $\$ 45.87$ & $\$ 19.59$ & $\$ 2.97$ & $\$ 30.25$ \\
\hline \multicolumn{5}{|l|}{ Optimization } \\
\hline Load (W/switch) & \multicolumn{4}{|c|}{73} \\
\hline $150 \mathrm{C}$ - max. projected junction temperature & 133.8 & 135.0 & 0 & 136.7 \\
\hline EG BP @ 16psig - max. fluid temperature & 123.7 & 124.1 & 124.7 & 0 \\
\hline
\end{tabular}

Table 9. Design 2 matrix summary using aluminum foam

\begin{tabular}{|c|c|c|c|c|}
\hline \multirow{3}{*}{$\begin{array}{l}\text { Design } \\
\text { Description } \\
\text { Ceramic insulator }\end{array}$} & \multicolumn{4}{|c|}{2} \\
\hline & \multicolumn{4}{|c|}{4 holes $5.7 \mathrm{~mm}$ diameter } \\
\hline & AlN & $\mathrm{BeO}$ & Alumina & $\mathrm{SiC}$ \\
\hline \multicolumn{5}{|l|}{ Copper foam (10 ppi, 8\% $\left.\rho_{\text {rel }}\right)$} \\
\hline Aluminum foam (10 ppi, $\left.8 \% \rho_{\text {rel }}\right)$ & \multicolumn{4}{|c|}{$\sqrt{ }$} \\
\hline Load (W/switch) & \multirow{2}{*}{\multicolumn{4}{|c|}{55}} \\
\hline \multicolumn{4}{|l|}{ Performance at 2.5 GPM for entire inverter } & \\
\hline Max projected junction temperature & 129.3 & 130.6 & 171.5 & 131.9 \\
\hline Max. fluid temperature & 122.7 & 123.1 & 133.4 & 123.7 \\
\hline Pass 1-mm particle & \multicolumn{4}{|c|}{ Probably } \\
\hline Compatible with WEG & & $\sqrt{ }$ & $\sqrt{ }$ & $\sqrt{ }$ \\
\hline \multicolumn{5}{|l|}{ Manufacturability } \\
\hline Smallest feature size (mm) & \multicolumn{4}{|c|}{5.7} \\
\hline Post processing (assembly, machining...) & \multirow{2}{*}{\multicolumn{4}{|c|}{ Foam insert }} \\
\hline Trade-offs to meet design criteria & & & & \\
\hline Required flow rate (GPM) & 2.5 & 2.5 & 3.88 & 2.5 \\
\hline Filter & \multicolumn{4}{|c|}{ Possibly } \\
\hline Cost per ceramic rated from 100,000 pcs. & $\$ 45.87$ & $\$ 19.59$ & $\$ 2.97$ & $\$ 30.25$ \\
\hline \multicolumn{5}{|l|}{ Optimization } \\
\hline Load (W/switch) & \multicolumn{4}{|c|}{73} \\
\hline $150 \mathrm{C}$ - max. projected junction temperature & 137.8 & 139.0 & 0 & 140.8 \\
\hline EG BP @ 16psig - max. fluid temperature & 128.5 & 129.1 & 0 & 129.9 \\
\hline
\end{tabular}


Table 10. Design 3 matrix summary using copper foam

\begin{tabular}{|c|c|c|c|c|}
\hline Design & \multicolumn{4}{|c|}{3} \\
\hline Description & \multicolumn{4}{|c|}{1 hole $9.0 \mathrm{~mm}$ diameter } \\
\hline Ceramic insulator & AlN & $\mathrm{BeO}$ & Alumina & $\mathrm{SiC}$ \\
\hline Copper foam (10 ppi, 8\% $\left.\rho_{\text {rel }}\right)$ & \multicolumn{4}{|c|}{$\sqrt{ }$} \\
\hline Aluminum foam ( $\left.10 \mathrm{ppi}, 8 \% \rho_{\mathrm{rel}}\right)$ & & & & \\
\hline Load (W/switch) & \multicolumn{4}{|c|}{55} \\
\hline \multicolumn{5}{|l|}{ Performance at 2.5 GPM for entire inverter } \\
\hline Max projected junction temperature & 137.3 & 138.8 & 219.5 & 140.9 \\
\hline Max. fluid temperature & 120.5 & 120.6 & 121.4 & 120.7 \\
\hline Pass 1-mm particle & \multicolumn{4}{|c|}{ Probably } \\
\hline Compatible with WEG & & $\sqrt{ }$ & $\sqrt{ }$ & $\sqrt{ }$ \\
\hline \multicolumn{5}{|l|}{ Manufacturability } \\
\hline Smallest feature size (mm) & \multicolumn{4}{|c|}{9.0} \\
\hline Post processing (assembly, machining...) & \multirow{2}{*}{\multicolumn{4}{|c|}{ Foam insert }} \\
\hline Trade-offs to meet design criteria & & & & \\
\hline Required flow rate (GPM) & 2.5 & 2.5 & Large & 2.5 \\
\hline Filter & \multicolumn{4}{|c|}{ Possibly } \\
\hline Cost per ceramic rated from 100,000 pcs. & $\$ 45.87$ & $\$ 19.59$ & $\$ 2.97$ & $\$ 30.25$ \\
\hline \multicolumn{5}{|l|}{ Optimization } \\
\hline Load (W/switch) & \multicolumn{4}{|c|}{73} \\
\hline $150 \mathrm{C}$ - max. projected junction temperature & 147.9 & 149.9 & 0 & 150.0 \\
\hline EG BP @ 16psig - max. fluid temperature & 125.6 & 125.7 & 124.7 & 125.8 \\
\hline
\end{tabular}

Table 11. Design 3 matrix summary using aluminum foam

\begin{tabular}{|c|c|c|c|c|}
\hline Design & \multicolumn{4}{|c|}{3} \\
\hline Description & \multicolumn{4}{|c|}{1 hole $9.0 \mathrm{~mm}$ diameter } \\
\hline Ceramic insulator & AlN & $\mathrm{BeO}$ & Alumina & $\mathrm{SiC}$ \\
\hline \multicolumn{5}{|l|}{ Copper foam (10 ppi, 8\% $\left.\rho_{\text {rel }}\right)$} \\
\hline Aluminum foam (10 ppi, $8 \%$ p rel $)$ & \multicolumn{4}{|c|}{$\sqrt{ }$} \\
\hline Load (W/switch) & \multirow{2}{*}{\multicolumn{4}{|c|}{55}} \\
\hline Performance at 2.5 GPM for entire inverter & & & & \\
\hline Max projected junction temperature & 142.3 & 143.8 & 224.4 & 145.9 \\
\hline Max. fluid temperature & 126.1 & 126.3 & 127.9 & 126.4 \\
\hline Pass 1-mm particle & \multicolumn{4}{|c|}{ Probably } \\
\hline Compatible with WEG & & $\sqrt{ }$ & $\sqrt{ }$ & $\sqrt{ }$ \\
\hline \multicolumn{5}{|l|}{ Manufacturability } \\
\hline Smallest feature size (mm) & \multicolumn{4}{|c|}{9.0} \\
\hline Post processing (assembly, machining...) & \multirow{2}{*}{\multicolumn{4}{|c|}{ Foam insert }} \\
\hline Trade-offs to meet design criteria & & & & \\
\hline Required flow rate (GPM) & 2.5 & 2.5 & Large & 2.5 \\
\hline Filter & \multicolumn{4}{|c|}{ Possibly } \\
\hline Cost per ceramic rated from 100,000 pcs. & $\$ 45.87$ & $\$ 19.59$ & $\$ 2.97$ & $\$ 30.25$ \\
\hline \multicolumn{5}{|l|}{ Optimization } \\
\hline Load (W/switch) & \multicolumn{4}{|c|}{73} \\
\hline $150 \mathrm{C}$ - max. projected junction temperature & $\mathrm{n} / \mathrm{a}$ & $\mathrm{n} / \mathrm{a}$ & $\mathrm{n} / \mathrm{a}$ & $\mathrm{n} / \mathrm{a}$ \\
\hline EG BP @ 16psig - max. fluid temperature & $\mathrm{n} / \mathrm{a}$ & $\mathrm{n} / \mathrm{a}$ & $\mathrm{n} / \mathrm{a}$ & $\mathrm{n} / \mathrm{a}$ \\
\hline
\end{tabular}


Table 12. Design 4 matrix summary using aluminum foam

\begin{tabular}{|c|c|c|c|c|}
\hline Design & \multicolumn{4}{|c|}{4} \\
\hline Description & \multicolumn{4}{|c|}{$24 \mathrm{~mm}$ face, annular flow channel } \\
\hline Ceramic insulator & AlN & $\mathrm{BeO}$ & Alumina & $\mathrm{SiC}$ \\
\hline Copper foam (10 ppi, 8\% $\left.\rho_{\text {rel }}\right)$ & & & & \\
\hline Aluminum foam (10 ppi, $\left.8 \% \rho_{\text {rel }}\right)$ & \multicolumn{4}{|c|}{$\sqrt{ }$} \\
\hline Load (W/switch) & \multicolumn{4}{|c|}{55} \\
\hline Performance at 2.5 GPM for entire inverter & & & & \\
\hline Max projected junction temperature & $\mathrm{n} / \mathrm{a}$ & $\mathrm{n} / \mathrm{a}$ & 152.0 & $\mathrm{n} / \mathrm{a}$ \\
\hline Max. fluid temperature & $\mathrm{n} / \mathrm{a}$ & $\mathrm{n} / \mathrm{a}$ & 124.0 & $\mathrm{n} / \mathrm{a}$ \\
\hline Pass 1-mm particle & \multicolumn{4}{|c|}{ Probably } \\
\hline Compatible with WEG & & & $\sqrt{ }$ & \\
\hline \multicolumn{5}{|l|}{ Manufacturability } \\
\hline Smallest feature size $(\mathrm{mm})$ & \multicolumn{4}{|c|}{5.0} \\
\hline Post processing (assembly, machining...) & \multirow{2}{*}{\multicolumn{4}{|c|}{ Foam insert }} \\
\hline Trade-offs to meet design criteria & & & & \\
\hline Required flow rate (GPM) & 2.5 & 2.5 & 2.5 & 2.5 \\
\hline Filter & \multicolumn{4}{|c|}{ Possibly } \\
\hline Cost per ceramic rated from 100,000 pcs. & $X$ & $\mathrm{X}$ & $\$ 2.97$ & $\mathrm{X}$ \\
\hline \multicolumn{5}{|l|}{ Optimization } \\
\hline Load (W/switch) & \multicolumn{4}{|c|}{73} \\
\hline $150 \mathrm{C}$ - max. projected junction temperature & $\mathrm{n} / \mathrm{a}$ & $\mathrm{n} / \mathrm{a}$ & $\mathrm{n} / \mathrm{a}$ & $\mathrm{n} / \mathrm{a}$ \\
\hline EG BP @ 16psig - max. fluid temperature & $\mathrm{n} / \mathrm{a}$ & $\mathrm{n} / \mathrm{a}$ & $\mathrm{n} / \mathrm{a}$ & $\mathrm{n} / \mathrm{a}$ \\
\hline
\end{tabular}

Table 13. Design 5 matrix summary using aluminum foam

\begin{tabular}{|c|c|c|c|c|}
\hline Design & \multicolumn{4}{|c|}{5} \\
\hline Description & \multicolumn{4}{|c|}{$\begin{array}{l}24 \mathrm{~mm} \text { face, } 4 \text { holes } 9.8 \mathrm{~mm} \text { diameter, offset } \\
2 \mathrm{~mm} \text { from center of chip }\end{array}$} \\
\hline Ceramic insulator & AlN & $\mathrm{BeO}$ & Alumina & $\mathrm{SiC}$ \\
\hline Copper foam (10 ppi, 8\% $\left.\rho_{\text {rel }}\right)$ & & & & \\
\hline Aluminum foam (10 ppi, $\left.8 \% \rho_{\text {rel }}\right)$ & \multicolumn{4}{|c|}{$\sqrt{ }$} \\
\hline Load (W/switch) & \multicolumn{4}{|c|}{55 per IGBT, 37 per diode } \\
\hline Performance at 2.5 GPM for entire inverter & & & & \\
\hline Max projected junction temperature & $\mathrm{n} / \mathrm{a}$ & $\mathrm{n} / \mathrm{a}$ & 150.3 & $\mathrm{n} / \mathrm{a}$ \\
\hline Max. fluid temperature & $\mathrm{n} / \mathrm{a}$ & $\mathrm{n} / \mathrm{a}$ & 128.5 & $\mathrm{n} / \mathrm{a}$ \\
\hline Pass 1-mm particle & \multicolumn{4}{|c|}{ Probably } \\
\hline Compatible with WEG & & & $\sqrt{ }$ & \\
\hline Manufacturability & & & & \\
\hline Smallest feature size (mm) & \multicolumn{4}{|c|}{5.0} \\
\hline Post processing (assembly, machining...) & \multicolumn{4}{|c|}{ Foam insert } \\
\hline Trade-offs to meet design criteria & & & & \\
\hline Required flow rate (GPM) & 2.5 & 2.5 & 2.5 & 2.5 \\
\hline Filter & \multicolumn{4}{|c|}{ Possibly } \\
\hline Cost per ceramic rated from 100,000 pcs. & $\mathrm{X}$ & $\mathrm{X}$ & $\$ 2.97$ & $\mathrm{X}$ \\
\hline Optimization & & & & \\
\hline Load (W/chip) & \multicolumn{4}{|c|}{73} \\
\hline $150 \mathrm{C}$ - max. projected junction temperature & $\mathrm{n} / \mathrm{a}$ & $\mathrm{n} / \mathrm{a}$ & $\mathrm{n} / \mathrm{a}$ & $\mathrm{n} / \mathrm{a}$ \\
\hline EG BP @ 16psig - max. fluid temperature & $\mathrm{n} / \mathrm{a}$ & $\mathrm{n} / \mathrm{a}$ & $\mathrm{n} / \mathrm{a}$ & $\mathrm{n} / \mathrm{a}$ \\
\hline
\end{tabular}

FEAs of the minimum and maximum principal stresses induced by thermal cycling were run only on the preferred Designs 4 and 5. This was to determine if $\mathrm{Al}_{2} \mathrm{O}_{3}$, having a lower thermal conductivity, could 
withstand the temperature-induced stress without failure. The higher-thermal-conductivity materials could inherently withstand higher stress values and not fail. All of the temperature values are close to that of the $\mathrm{Al}_{2} \mathrm{O}_{3}$ design, so stress should not be a factor in the higher-thermal-conductivity materials. The two designs (4 and 5) meet the OEM’s cost and performance targets.

\subsection{COST COMPARISON}

The directly cooled power electronics substrate project is a new concept and therefore untried in industry. Costs can be quantified on conventional inverter architectures based on component purchase prices, material costs and manufacturing assembly costs. What can be determined in this research effort are material extrusion costs, fabrication costs for ceramic components, and estimated cost savings from the elimination of the conventional heat sink, the base plate/heat spreader, and the TIM. Each of the ceramic fabrication costs is listed in Table 14 and is based on material and tooling costs per 100,000 pieces.

Table 14. Cost summary for ceramic materials considered in the fabrication of a direct-cooled power electronics substrate

\begin{tabular}{|c|c|c|c|c|}
\hline Description & $\begin{array}{c}\text { Material } \\
\text { extrusion cost }\end{array}$ & $\begin{array}{c}\text { Copper } \\
\text { plating }\end{array}$ & $\begin{array}{c}\text { Purchase } \\
\text { price }\end{array}$ & $\begin{array}{c}\text { Total cost per } \\
\text { inverter }\end{array}$ \\
\hline $\mathrm{AlN}$ & $\$ 45.87$ & $\$ 3.12$ & $\$ 48.99$ & $\$ 293.94$ \\
\hline $\mathrm{Al}_{2} \mathrm{O}_{3}$ & $\$ 2.97$ & $\$ 3.12$ & $\$ 6.09$ & $\$ 36.54$ \\
\hline $\mathrm{SiC}$ & $\$ 30.25$ & $\$ 3.12$ & $\$ 33.37$ & $\$ 200.22$ \\
\hline $\mathrm{BeO}$ & $\$ 19.59$ & $\$ 3.12$ & $\$ 22.71$ & $\$ 136.26$ \\
\hline
\end{tabular}

If the ceramic of choice in the final inverter design was $\mathrm{Al}_{2} \mathrm{O}_{3}$, based on the information in Table 14, the cost to produce the copper-plated ceramic substrate in a quantity of 100,000 units would be approximately \$36.54. The savings compared with a conventional inverter, such as Semikron, would be $\$ 64.02$ from just the elimination of the heat sink and the base plate. Additional savings will be realized by the elimination of the TIM, and there would be a weight savings of $\sim 3 \mathrm{~kg}$ per inverter in this research effort because the base plate and heat sink would not be required. These cost savings do not take into account the wire bonds, the cost of the IGBTs and diodes, or the capacitor since it is expected these costs will be comparable to the current Semikron inverter in mass production. 


\subsection{SUMMARY}

Directly cooling an $\mathrm{Al}_{2} \mathrm{O}_{3}$ ceramic substrate with $105^{\circ} \mathrm{C}$ coolant while maintaining silicon temperatures below their maximum operation temperature is viable and cost-effective. The shape of the substrate, size and shape of the capacitor, coolant flow channels, metallic foam flow channel inserts, and chip population on the substrate all play a key role. Because of cost limitations, Designs 1-3 had to be modified in order to meet the design goals. These changes resulted in the development of Designs 4 and 5. The designs explored all have hexagonal cross-sections. This configuration was chosen because the required surface area could be obtained within the smallest package volume. These substrates would be joined by a manifold which is placed inside the inner diameter of a hollow capacitor. Additionally, the hexagonal shape, with round ends, is far easier to seal from the coolant than other types of planer structural shapes. This design layout is similar to that of the refrigerant-cooled inverter researched by ORNL [6].

The addition of a thermal enhancer, such as aluminum foam, into the flow channels provided a greater surface area within the flow channel to remove the waste heat more efficiently. This material has a much higher structural integrity than other types of microstructures and provides a simple means of manufacture. FEA results were run using both aluminum and copper foam; however, cost, availability, and environmental concerns due to the manufacturability of the copper foam steered this research effort towards aluminum foam.

The capacitor(s) necessary to complete the inverter design dictates the overall volume of the direct-cooled power electronics substrate. Since this component has a larger volume than many of the other required components, volume reduction can be limited by the physical size of the capacitor and the capacitance required for inverter operation. Based on capacitor designs obtained from the SBE, Inc. Power Ring division, the preferred design in this research and development effort has a power density approaching $14 \mathrm{~kW} / \mathrm{l}$. However, this preferred design uses a ceramic substrate with a high-thermal-conductivity capability, which comes at a higher cost. If the lower cost ceramic substrate such as $\mathrm{Al}_{2} \mathrm{O}_{3}$ is used, the cost is significantly reduced; but the power density approaches $7.5 \mathrm{~kW} / \mathrm{l}$ because of the size of the substrate necessary to spread the thermal load.

Performance testing of Designs 4 and 5 will be performed to validate the FEA results. These designs meet the specified design criteria while providing a lower cost to the OEMs. Designs 2 and 3 also met the specified design criteria but at a higher cost. They could be constructed with three or four chips as long as the coolant system pressure is kept high enough to prevent boiling but low enough such that the OEMs do not have to alter conventional radiator components. For initial bench testing in FY 2009, diodes will be used on Designs 4 and 5 to generate the waste heat needed to validate the modeling. Fewer silicon switching devices could be implemented in the final architectures so long as the experimentation supports the modeling results. 


\section{REFERENCES}

1. Chung-Daw Young and Jeng-Gong Duh, "Corrosion of Aluminum Nitride Substrates in Acid, Alkaline Solutions and Water,” pp. 185-195 in Journal of Materials Science, 30(1), January 1, 1995.

2. S. Fukumoto, T. Hookabe and H. Tsubakino, "Hydrolysis Behavior of Aluminum Nitride in Various Solutions,” pp. 2743-2748 in Journal of Materials Science, 35(11), June 2000.

3. Testing of the Semikron Validation AIPM Unit at the Oak Ridge National Laboratory, ORNL/TM2005/44, January 2005.

4. P. Salvati, F. Brucchi, and A. De Mdici, “Application Note: Sinusoidal Inverter using SEMITOP® Modules for Electric Vehicles Applications," Semikron.

5. V. V. Calmidi and R. L. Mahajan, "The Effective Thermal Conductivity of High Porosity Fibrous Metal Foams,” pp. 466-471 in Journal of Heat Transfer, 121, 1999.

6. Annual Progress Report for the Advanced Power Electronics and Electric Machinery Program, 2.1 Thermal Control for Inverters and Motors, Oak Ridge National Laboratory, 2007. 


\section{PATENTS}

1. R. H. Wiles, A. A. Wereszczak, C. W. Ayers, and K. T. Lowe, Direct Cooled Power Electronics Substrate, provisional patent number 61/037,129, March 17, 2008. 


\section{DISTRIBUTION}

\section{Internal}

\author{
1. D. J. Adams \\ 2. C. W. Ayers \\ 3. K. P. Gambrell \\ 4. E. C. Fox \\ 5. D. R. Johnson \\ 6. H.-T. Lin \\ 7. K. T. Lowe
}

8. L. D. Marlino

9. M. Olszewski

10. D. P. Stinton

11. A. Wereszczak

12. R. H. Wiles

13. Laboratory Records

\section{External}

14. R.Al-Attar, DCX, raa9@chrysler.com.

15. S. J. Boyd, U.S. Department of Energy, EE-2G/Forrestal Building, 1000 Independence Avenue, S.W., Washington, D.C. 20585.

16. J. Czubay, General Motors Corporation, GM Powertrain Headquarters, Mail Code: 483-710-270, 895 Joslyn Avenue, Pontiac, Michigan 48340.

17. H. Dadkhah, Chrysler, LLC, CIMS 526-00-00, 1960 Technology Drive, Building D, Troy, Michigan 48083.

18. P. B. Davis, U.S. Department of Energy, EE-2G/Forrestal Building, 1000 Independence Avenue, S.W., Washington, D.C. 20585.

19. R. R. Fessler, BIZTEK Consulting, Inc., 820 Roslyn Place, Evanston, Illinois 60201-1724.

20. S. Gopalakrishnan, General Motors Corporation, RMB-356, Mail Code 480-106-390, 30500 Mound Road, Warren, Michigan 48090.

21. G. Hagey, 501 Randolph St., Williamsburg, Virginia 23185.

22. E. Jih, Ford Motor Company, Scientific Research Laboratory, 2101 Village Road, MD-1170, Rm. 2331, Dearborn, Michigan 48121.

23. K. J. Kelly, National Renewable Energy Laboratory, 1617 Cole Boulevard, Golden, Colorado 80401.

24. F. Leonardi, Ford Motor Company, 15050 Commerce Drive, North, Dearborn, Michigan 481201261.

25. F. Liang, Ford Motor Company, Scientific Research Laboratory, 2101 Village Road, MD1170, Rm. 2331/SRL, Dearborn, Michigan 48121.

26. M. W. Lloyd, Energetics, Inc., 7164 Columbia Gateway Drive, Columbia, Maryland 21046.

27. M. Mehall, Ford Motor Company, Scientific Research Laboratory, 2101 Village Road, MD-2247, Rm. 3317, Dearborn, Michigan 48124-2053.

28. N. Olds, United States Council for Automotive Research (USCAR),nolds@uscar.org

29. S. A. Rogers, U.S. Department of Energy, EE-2G/Forrestal Building, 1000 Independence Avenue, S.W., Washington, D.C. 20585.

30. G. S. Smith, General Motors Advanced Technology Center, 3050 Lomita Boulevard, Torrance, California 90505.

31. R. A. Sullivan, U.S. Department of Energy, EE-2G/Forrestal Building, 1000 Independence Avenue, S.W., Washington, D.C. 20585. 